\author{
UNIVERSIDADE DE SÃO PAULO \\ FACULDADE DE ODONTOLOGIA DE BAURU
}

RAFAEL MASSUNARI MAENOSONO

RESISTÊNCIA DE UNIÃO À DENTINA DE SISTEMAS ADESIVOS IRRADIADOS COM LASER DE DIODO: ESTUDO IN VITRO 

RAFAEL MASSUNARI MAENOSONO

\section{RESISTÊNCIA DE UNIÃO À DENTINA DE SISTEMAS ADESIVOS IRRADIADOS COM LASER DE DIODO: ESTUDO IN VITRO}

Dissertação apresentada a Faculdade de Odontologia de Bauru da Universidade de São Paulo para obtenção do título de Mestre em Ciências no Programa de Ciências Odontológicas Aplicadas, na área de concentração Dentística.

Orientador: Prof. Dr. Sérgio Kiyoshi Ishikiriama

Versão corrigida 


\begin{tabular}{|c|c|}
\hline M268r & $\begin{array}{l}\text { Maenosono, R. M. } \\
\quad \text { Resistência de união à dentina de sistemas } \\
\text { adesivos irradiados com laser de diodo: estudo in } \\
\text { vitro / Rafael Massunari Maenosono. - Bauru, } \\
\text { 2013. } \\
\quad 102 \text { p. : il. ; } 31 \mathrm{~cm} \text {. }\end{array}$ \\
\hline & $\begin{array}{l}\text { Tese/Dissertação (Doutorado/Mestrado) - } \\
\text { Faculdade de Odontologia de Bauru. Universidade } \\
\text { de São Paulo }\end{array}$ \\
\hline & $\begin{array}{l}\text { Orientador: Prof. Dr. Sérgio Kiyoshi } \\
\text { Ishikiriama }\end{array}$ \\
\hline
\end{tabular}

Nota: A versão original desta dissertação encontra-se disponível no Serviço de Biblioteca e Documentação da Faculdade de Odontologia de Bauru - FOB/USP

Autorizo, exclusivamente para fins acadêmicos e científicos, a reprodução total ou parcial desta dissertação/tese, por processos fotocopiadores e outros meios eletrônicos.

Assinatura:

Data:

Comitê de Ética da FOB-USP

Protocolo no: 111.666

Data: $26 / 09 / 2012$ 


\section{DEDICATÓRIA}

Dedico este trabalho à minha família, fonte de minha inspiração, perseverança e determinação. Ao meu sábio e valente pai, Emílio Akira Maenosono, à minha eficiente e carinhosa mãe, Regina Tomie Massunari Maenosono, ao meu forte e generoso irmão, Edgar Massunari Maenosono, e à minha doce e amada companheira Denise Ferracioli Oda. 



\section{AGRADECIMENTOS}

Agradeço a DEUS por permitir que minha trajetória fosse sempre tão feliz, e que mesmo nos momentos mais adversos eu pudesse contar com suas bênçãos, vindas sempre através destas pessoas iluminadas que o Senhor fez cruzar o meu caminho.

Agradeço aos meus pais, Emílio Akira Maenosono e Regina Tomie Massunari Maenosono, pela oportunidade de estudar, pelo carinho, pela compreensão, pelo incentivo, pelo exemplo de perseverança e pelo amor que posso sentir a cada telefonema e a cada visita, que me fortalece e me faz seguir em frente independente do obstáculo que me desafia. Obrigado pela felicidade que me proporcionaram desde meu primeiro segundo de vida, até hoje, e infinitamente.

Agradeço ao meu grande irmão, Edgar Massunari Maenosono, pela prestatividade e companheirismo cruciais com que pude contar nos momentos mais adversos que passei. Sua presença tornou Bauru mais confortável, com mais "cara de casa", e permitiu que eu me desenvolvesse ao máximo profissionalmente. Obrigado por também ter escolhido a FOB para que pudéssemos morar juntos e nos tornarmos ainda mais unidos!

Agradeço à Denise Ferracioli Oda, minha companheira eterna, amor da minha vida. Sua companhia me transforma, e me cura de todo mal que possa ter me infectado nesta vida virulenta. Quando ao seu lado, a felicidade deixa de ser um objetivo, e passa a ser realidade constante. Que DEUS permita que eu viva esta felicidade contigo pelo resto de minha vida.

Agradeço a todos os meus professores pelo esforço em transmitir seus conhecimentos e suas experiências. Em especial agradeço ao meu orientador, Prof. Dr. Sérgio Kiyoshi Ishikiriama, um sábio da modernidade, mestre da didática, e senhor do equilíbrio e da humildade. Obrigado pela intensa transmissão de conhecimento clínico e teórico, mas sobretudo obrigado por mostrar a existência de um caminho em que a humildade, dedicação e disciplina podem fazer a diferença. 

Aproveito para agradecer à sua esposa, Profª. Dra.. Bella Luna Colombini Ishikiriama, pela excelente convivência que sempre tivemos, pelas oportunidades que sempre tem oferecido para mim e para Denise, e principalmente pelas palavras de incentivo que muito me alegram, e me fortalecem.

Agradeço também em especial ao Prof. Dr. Eduardo Batista Franco. Assim como o "Guga" nas quadras, o "Senna" nas pistas, e o "Pelé" nos campos de futebol, o Prof. Eduardo é o grande "craque" da Dentística. À este perfeito exemplo de professor, agradeço pelo entusiasmo e pela dedicação às atividades da graduação e pós-graduação, que com certeza proporcionaram o diferencial de minha formação profissional. Muitas de suas convicções serão eternizadas através de minha pessoa para todos os alunos com quem eu tiver a oportunidade de conviver.

Agradeço à Profá. Dra. Linda Wang por toda dedicação e empenho em nos proporcionar um mestrado tão rico como foi o de nossa turma. As horas extras desta dedicação certamente não serão recompensadas financeiramente, no entanto, estarão gravadas eternamente em nossos corações. Em especial obrigado por literalmente pegar na minha mão para ensinar a escrever projetos de pesquisa, introduções, revisões e etc. A presença de professores como a senhora, na FOB, nos dá a certeza de que a nossa casa continuará brilhando como uma das melhores faculdades de odontologia do mundo.

Agradeço à Profa. . Dra. Regina Guenka Palma-Dibb, por nos proporcionar os conhecimentos fundamentais para o desenvolvimento desta dissertação, assim como equipamentos e acessórios. Obrigado pela maneira sempre gentil e alegre que nos recebe em sua sala, e pelo tempo dedicado às nossas infindáveis dúvidas que trazemos a cada viagem.

Agradeço ao Prof. Dr. Marco Húngaro, o querido Sal, não só pelo auxílio com a análise estatística, mas principalmente pelo exemplo de inovação e determinação com que renova as forças da tradicional Endodontia da FOB-USP. 

Agradeço também ao Prof. Dr. Rafael Francisco Lia Mondelli pela maestria com que lidera a Dentística, à Profa. Dra. Maria Teresa Atta pelo ensino da filosofia da própria vida e pelo empenho prestado à nossa querida graduação de odontologia.

Agradeço ao Prof. Dr. Carlos Eduardo Francischone pelo enorme conhecimento clínico transmitido na clínica de restaurações indiretas, ao Prof. Dr. Aquira Ishikiriama pelo conhecimento prático e teórico de anatomia e escultura dentária que pude desfrutar mais uma vez, agora auxiliando-o nos laboratórios de escultura do $1^{\circ}$ ano.

Agradeço também ao Prof. Dr. José Mondelli, cuja alegria e ousadia de inovar são contagiantes. À Profá. Drª. Ana Flávia Sanches Borges e ao Prof. Dr. Paulo Afonso Francisconi pela profundidade e pela alegria que conduziram nossas disciplinas de materiais dentários.

Agradeço aos companheiros de pós-graduação por toda excelente convivência, e pela integração, que nos fez crescer juntos e mais fortes. Em especial agradeço aos amigos Juan, Carlos, Odair, Ana Flávia, Damaris, Diana, Marina, Raphaela, Carla, Leslie, Maria Cristina, Guilherme, Carol, Larissa, Gabriel Barbério e Lucas Mendes pela amizade e pelos bons momentos vividos durante este período.

Agradeço aos funcionários do Departamento de Dentística, Endodontia e Materiais Odontológicos, em especial ao Seu Nelson e ao Alcídes pela alegria nos momentos de convivência, à Rita, Sandra e à Beth pela paciência e atenção que tem conosco auxiliando-nos com toda documentação, à Natália, à Áudria e à Charlene, novas funcionárias que literalmente vestiram a camisa da FOB e têm toda minha admiração, e à Zuleica, Elísio e Lígia que completam o quadro formidável de funcionários da dentística que formam uma verdadeira família.

Em nome da bibliotecária Cybelle Fontes também agradeço à toda a equipe da biblioteca da FOB-USP por proporcionar um acervo tão rico e organizado sobre a literatura odontológica mundial, e por nos ajudar de forma tão humana em todos os momentos. 

Agradeço aos alunos de graduação pela amizade e pela alegria que transparece durante os laboratórios e clínicas, além de toda a convivência externa. Em especial agradeço à 48 ${ }^{\mathrm{a}}$ Turma de Odontologia "Prof ${ }^{\mathrm{a}}$ Dra Maria Teresa Atta" por proporcionarem um dos dias mais emocionantes e felizes da minha vida, ao me escolherem como seu pós-graduando homenageado. É uma honra que ficará guardada eternamente em meu coração. 



\section{AGRADECIMENTOS INSTITUCIONAIS}

Ao Prof. Dr. João Grandino Rodas, digníssimo reitor da Universidade de São Paulo.

Ao Prof. Dr. José Carlos Pereira, digníssimo Diretor da Faculdade de Odontologia de Bauru da Universidade de São Paulo.

Ao Prof. Dr. José Roberto Pereira Lauris, Prefeito do Campus da Faculdade de Odontologia de Bauru da Universidade de São Paulo.

Ao Prof. Dr. Paulo César Rodrigues Conti, Presidente da Comissão de PósGraduação da Faculdade de Odontologia de Bauru da Universidade de São Paulo.

Ao Conselho Nacional de Desenvolvimento Científico e Tecnológico (CNPq), órgão de fomento de meu mestrado (processo 134356/2011-0). 

"Seja um sonhador, mas una seus sonhos com disciplina, pois sonhos sem disciplina produzem pessoas frustradas, que nunca transformam seus sonhos em realidade, e disciplina sem sonhos produz servos, pessoas que executam ordens, que fazem tudo automaticamente, e sem pensar." 



\section{RESUMO}

A irradiação LASER sobre os sistemas adesivos aplicados em dentina, antes de sua fotoativação, tem sido proposta para aumentar a resistência de união de restaurações adesivas. O objetivo foi avaliar o efeito da irradiação com LASER de Diodo $(\lambda=970 \mathrm{~nm})$ sobre diferentes sistemas adesivos na resistência de união imediata à dentina. Oitenta molares humanos hígidos foram aleatoriamente distribuídos em 8 grupos $(n=10)$ de acordo com o sistema adesivo: MP (Adper ${ }^{\mathrm{TM}}$ ScotchBond Multi-Purpose Plus - convencional não simplificado), SB (Adper ${ }^{\mathrm{TM}}$ SingleBond 2 - convencional simplificado), CSE (Clearfil ${ }^{\mathrm{TM}}$ SE Bond autocondicionante não simplificado), EO (AdperTM EasyOne - autocondicionante simplificado); e respectivos grupos irradiados com LASER de Diodo (SiroLaser, Sirona Dental). Para avaliar a resistência de união foi realizado teste de microtração, obtendo-se valores em MPa, posteriormente analisados através de ANOVA a 2 critérios, seguido de Tukey para comparações individuais e múltiplos testes " $t$ " $(p<0,05)$ para comparações entre CONTROLE e LASER do mesmo sistema adesivo. Os valores de resistência de união \pm desvio padrão para os grupos sem e com irradiação com LASER foram respectivamente: MP $(40,10 \pm 10,95$ / 35,82 $\pm 7,17)$, SB $(33,49 \pm 6,77$ / 43,69 $\pm 8,15)$, CSE $(43,71 \pm 15,71 / 37,95 \pm 7,66)$ e EO $(19,67 \pm 5,86 /$

$29,87 \pm 6,98)$. A irradiação com LASER de Diodo provocou um aumento da resistência de união obtida pelos sistemas adesivos SB e EO, mostrando-se uma técnica promissora na obtenção de uma adesão mais efetiva de sistemas adesivos simplificados ao substrato dentinário.

Palavras-chave: Adesivos. Lasers. Dentina. Resistência à tração. 



\section{ABSTRACT \\ Bond strength to dentin with adhesive systems irradiated with diode laser: in vitro study}

LASER irradiation on adhesive systems before it's activation has been proposed to increase bond strength of composite restorations to dentin. The objective was to evaluate the effect of Diode LASER irradiation ( $\lambda=970 \mathrm{~nm})$ on different adhesive systems on immediate bond strength to dentin. Eighty healthy human molars were randomly distributed in 8 groups $(n=10)$ according to the adhesive system: MP (Adper ${ }^{\mathrm{TM}}$ ScotchBond Multi-Purpose Plus, non simplified etch and rinse), SB (Adper ${ }^{\mathrm{TM}}$ SingleBond 2 - simplified etch and rinse), CSE (Clearfil ${ }^{\mathrm{TM}}$ SE Bond - non simplified self-etch), EO (Adper TM EasyOne - simplified self-etch); and respective groups irradiated with Diode LASER (SiroLaser, Sirona Dental). Microtensile test was performed obtaining bond strength values in MPa whice were analyzed by two way ANOVA, followed by Tukey for individual comparisons and multiple "t" test $(p<0.05)$ for evaluation of CONTROL and LASER groups with the same adhesive systems. Bond strength values \pm standard deviation for groups without and with LASER irradiation were respectively: MP (40.10 110.95 /

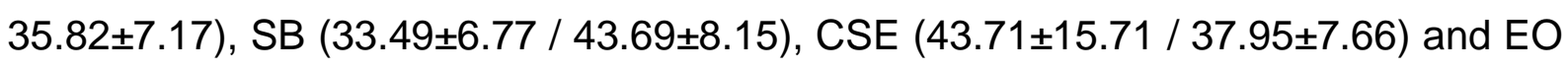

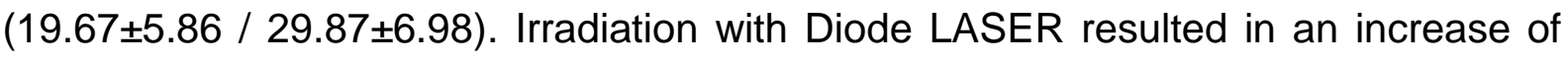
SB and EO bond strength values, being considered a promising technic to obtain an improved adhesion of simplified adhesive systems to dentin substrate.

Keywords: Adhesives. Lasers. Dentin. Tensile strength. 



\section{LISTA DE ILUSTRAÇÕES}

- FIGURAS

Figura 1 - O processo de emissão espontânea acontece quando um átomo ou molécula em seu estado de menor energia ou estado fundamental (A) recebe uma certa quantidade de energia, passando para um estado de semi-estabilidade mais energético, denominado estado metaestável (B). O átomo no estado metaestável regride espontaneamente para seu estado fundamental, liberando um fóton, cuja energia determina seu comprimento de onda (C). Adaptado de Tipler e Mosca (2009).

$E_{1}=$ Energia do estado mais energético; $E_{0}=$ Energia do estado fundamental; $h=$ constante de Planck; $c=$ velocidade da luz; $\lambda=$ comprimento de onda

Figura 2 - O processo de emissão estimulada acontece quando um átomo ou molécula já se apresenta no estado metaestável $(A)$ e recebe um fóton com quantidade de energia exatamente igual a $E_{1}-E_{0}$ (B). Esta energia causa um distúrbio no átomo, estimulando-o a regredir para o estado fundamental e liberar outro fóton, em fase e de mesma energia que o fóton incidente (C). Adaptado de Tipler e Mosca (2009).

Figura 3 - Figura 3: O LASER de Rubi consiste num cristal de rubi, com uma das extremidades completamente espelhada, e a outra refletindo $85 \%$ da luz, envolta por um tubo helicoidal que emite radiação* num espectro amplo. Esta radiação fornece energia para causar a inversão da população (maior quantidade de átomos no estado metaestável) e dar início aos processos de emissão espontânea e emissão* estimulada* ${ }^{*}$ que vão determinar amplificação* da luz*, resultando na propagação de um feixe de luz coerente e monocromático, com comprimento de onda definido.* Estas palavras foram o acrônimo LASER (Light Amplification by Stimulated Emission of Radiation) 

Figura 4 - Considere que para as três situações (A, B e C) a potência $(P)$, ou seja, a quantidade de energia irradiada por segundo, seja a mesma, no entanto, a área da secção transversal do feixe de luz (a) é alterada. Observe que quanto menor a espessura do feixe, maior é a densidade de potência (DP), e maior a capacidade de penetração da luz $(A)$, enquanto num feixe de luz mais espesso a penetração, assim como a densidade de potência são menores (C)

Figura 5 - A) Exemplo de LASER Nd:YAG (Smartfile, Deka, Calenzano, Itália): dimensões de $20 \times 37 \times 39 \mathrm{~cm}, 13 \mathrm{Kg}$, custo em torno de $\mathrm{R} \$ 100.000,00$. B) LASER de Diodo (SiroLaser, Sirona Dental

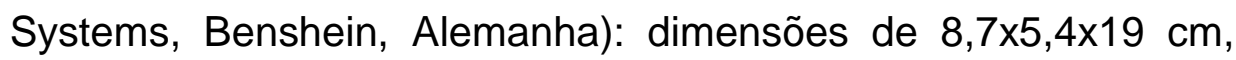
$450 \mathrm{~g}$ e custo em torno de $\mathrm{R} \$ 15.000,00$

Figura 6 - A) Matriz (M) de silicone de condensação de 6mm de largura por $6 \mathrm{~mm}$ de comprimento é posicionada de forma centralizada sobre a dentina, e esmalte de unha (E) é utilizado para delimitação da área a ser irradiada. B) Representação da área a ser irradiada (I) determinada através da utilização de esmalte de unha.

Figura 7 - A) Máquina de cortes seriados (Isomet ${ }^{\mathrm{TM}}$ Low Speed Saw ${ }^{\circledR}$, Buehler, Lake Bluff, EUA). B) O primeiro corte é realizado no sentido mésio-distal da coroa, gerando fatias de aproximadamente $1 \mathrm{~mm}$ de espessura. C) Corte semelhante é realizado, agora no sentido vestíbulo-lingual do mesmo dente, gerando palitos com área transversal de aproximadamente $1 \mathrm{~mm}^{2}$. 

Figura 8 - $O$ teste de microtração foi conduzido na máquina de ensaios universal INSTRON 3342 (A) (Illinois Tool Works, Norwood, EUA) utilizando-se dispositivo de microtração similar ao de Bencor multi T (T) (Danville Engeneering, Danville, CA, EUA) com célula de carga de $500 \mathrm{~N}(\mathrm{C})$. Os palitos foram fixados, com adesivo à base de cianocrilato (Loctite Super Bonder Gel Control, Henkel Ltda, São Paulo, Brasil) posicionando a interface adesiva perpendicular à força de tração (D)

Figura 9- A) Estereomicroscópio (Dino Lite Microscope 100x, AnMo Electronics Corp, New Taipei City, Taiwan) utilizado para análise de qualidade e de fratura. B) Presença de remanescente de esmalte de unha* determinou a exclusão deste espécime. C) Presença de adesivo cianoacrilato na interface adesiva compromete a avaliação da resistência de união e determina também a exclusão do espécime

Figura 10 - Imagens representativas de fraturas adesiva (A), coesiva em resina $(C R)$, coesiva em dentina $(C D)$ e mista $(M)$, obtidas com microscópio com aumento de 100x

- GRÁFICOS

Gráfico 1 - Representação gráfica das médias e desvio padrão da resistência de união obtida após testes de microtração (MPa)

Gráfico 2 - Representação gráfica da porcentagem do tipo de fratura ocorrido em cada grupo após o teste de microtração. 

- QUADROS

Quadro 1 - Descrição dos 4 grupos de sistemas adesivos utilizados atualmente....................................................................... 33

Quadro 2 - Outros tipos de LASER com comprimentos de onda distintos........ 38

Quadro 3 - Divisão dos grupos de acordo com os fatores de variação.............. 53

Quadro 4 - Composição química dos sistemas adesivos utilizados, de acordo com os fabricantes............................................................. 54

Quadro 5 - Aplicação dos sistemas adesivos segundo as orientações dos

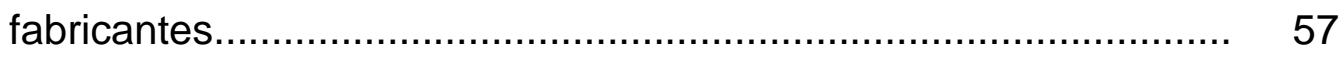

Quadro 6 - Parâmetros utilizados para irradiação da área teste com LASER de Diodo.................................................................................. 58 



\section{LISTA DE TABELAS}

Tabela 1 - Média \pm desvio padrão dos valores de resistência de união (MPa) agrupados no fator "Sistema Adesivo" ( $\mathrm{n}=20)$.

Tabela 2 - Média \pm desvio padrão dos valores de resistência de união (MPa) agrupados no fator "LASER" $(n=40)$.

Tabela 3 - Média \pm desvio padrão da resistência de união (MPa) obtida por cada grupo individualmente $(n=10)$

Tabela 4 - Porcentagem do tipo de fratura de cada grupo.

Tabela 5 - Relação entre os parâmetros utilizados com resultados obtidos em estudos que utilizaram o mesmo sistema adesivo (SB). 



\section{LISTA DE ABREVIATURA E SIGLAS}

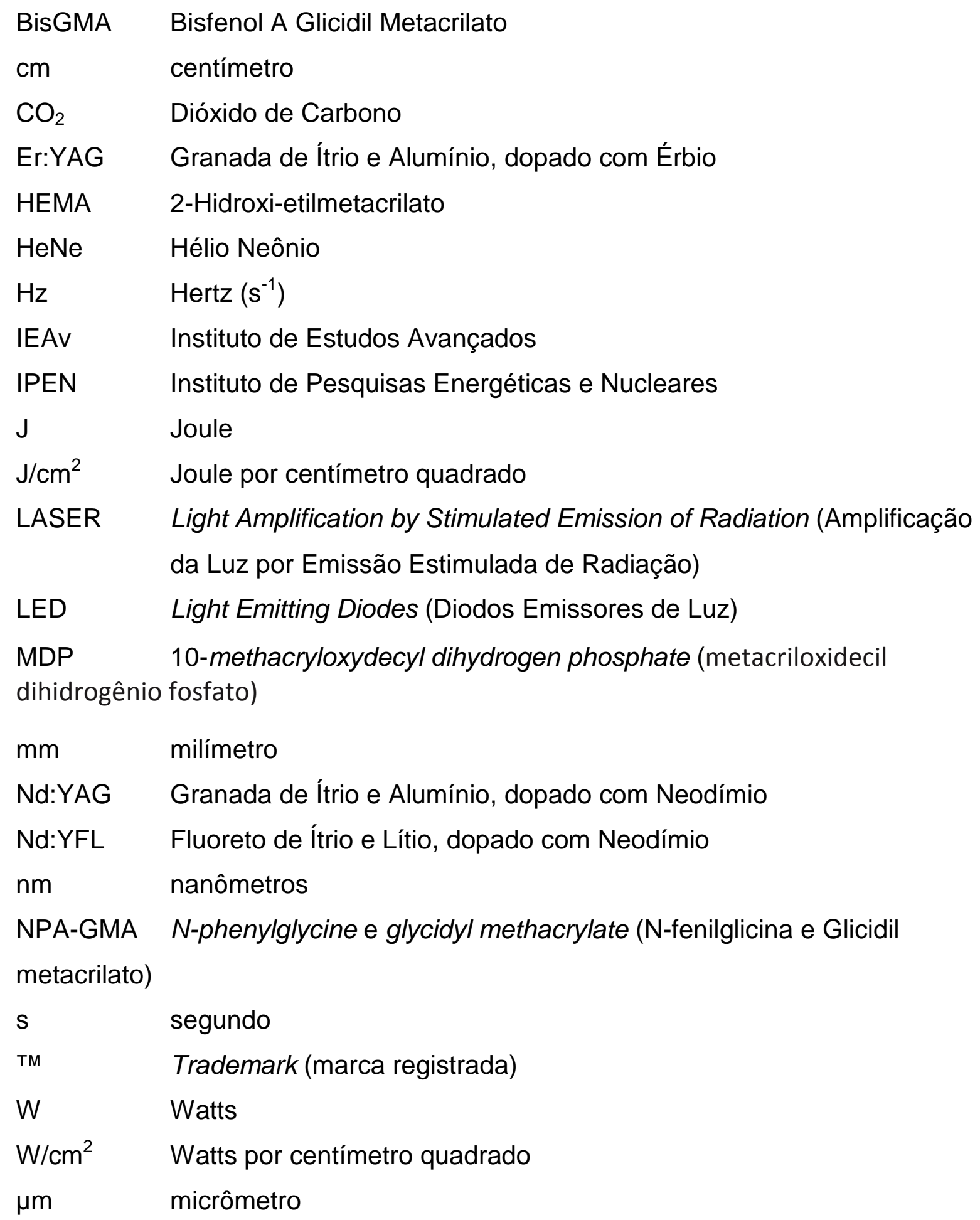





\section{LISTA DE SÍMBOLOS}

$\begin{array}{ll} \pm & \text { mais ou menos } \\ < & \text { menor } \\ \text { A } & \text { Área a ser irradiada } \\ \text { a } & \text { Área da secção transversal do feixe de luz } \\ \mathrm{C} & \text { Velocidade da Luz } \\ \mathrm{CSE} & \text { Clearfil }^{\mathrm{TM}} \text { SE Bond } \\ \mathrm{DE} & \text { Densidade de Energia } \\ \mathrm{DP} & \text { Densidade de Potência } \\ \mathrm{E}_{0} & \text { Energia do estado fundamental } \\ \mathrm{E}_{1} & \text { Energia do estado mais energético } \\ \mathrm{EO} & \text { AdperTM EasyOne } \\ \mathrm{Ep} & \text { Energia por pulso } \\ \mathrm{Et} & \text { Energia total } \\ \mathrm{F} & \text { Frequência } \\ \mathrm{h} & \text { Constante de Planck } \\ \mathrm{MP} & \text { AdperTM Scotchbond Multi-Purpose Plus } \\ \mathrm{P} & \text { Potência } \\ \mathrm{SB} & \text { AdperTM SingleBond } 2 \\ \lambda & \text { Comprimento de onda }\end{array}$





\section{SUMÁRIO}

1 INTRODUÇÃO 23

2 REVISÃO DE LITERATURA 29

2.1 ADESÃO 31

2.2 LASER 36

2.3 INFLUÊNCIA DA IRRADIAÇÃO LASER NA ADESÃO À DENTINA 43

3 PROPOSIÇÃO 47

4 MATERIAIS E MÉTODOS 51

4.1 DELINEAMENTO EXPERIMENTAL 53

4.2 OBTENÇÃO DOS DENTES HUMANOS 55

4.3 PLANIFICAÇÃO DAS COROAS PARA A EXPOSIÇÃO DA DENTINA

4.4 PREPARO DOS ESPÉCIMES 56

4.5 OBTENÇÃO DOS PALITOS 59

4.6 TESTE DE MICROTRAÇÃO 60

4.7 ANÁLISE DE FRATURA 61

4.8 ANÁLISE ESTATÍSTICA 62

5 RESULTADOS 63

6 DISCUSSÃO 69

7 CONCLUSÕES $\quad 77$

8 REFERÊNCIAS 81

9 APÊNDICES $\quad 89$

10 ANEXOS 99 

1 Introdução 

1 INTRODUÇÃO

As resinas compostas são um dos materiais restauradores mais versáteis e eficazes da odontologia atual, principalmente devido a sua estética e resistência satisfatória, além da capacidade de aderir à estrutura dentária (FERRACANE, 2011). A alta qualidade da adesão deste material ao esmalte determina um elevado índice de sucesso, com longevidade comparável às restaurações de amálgama, como observado em acompanhamento clínico de 10 anos (MERTZ-FAIRHURST et al., 1998). Por outro lado a união das resinas compostas à dentina ainda é considerada uma fraca ligação (SPENCER et al., 2010), uma vez que restaurações de resina com margens em dentina apresentam longevidade significantemente inferior às restaurações extensas de amálgama, mesmo com margens em dentina (MJOR; DAHL; MOORHEAR, 2000; SONCINI et al., 2007).

Diferentes estratégias têm sido pesquisadas e propostas para melhorar a qualidade da união entre o sistema adesivo e o substrato dentinário. Esta busca constante tem impulsionado os pesquisadores e a indústria no desenvolvimento de diferentes sistemas adesivos, que apesar de já apresentarem uma evolução perceptível, ainda são responsáveis por grande parte dos fracassos em restaurações adesivas.

Uma interessante proposta com o objetivo de melhorar a interação do sistema adesivo com à dentina consiste na utilização da tecnologia LASER. Stern e Soggnanes (1964) já observavam que o LASER poderia influenciar nas características morfológicas das estruturas dentárias, no entanto, apenas na década de 90 estudos foram realizados com o objetivo de aproveitar estas alterações em benefício da adesão dos sistemas adesivos.

Inicialmente foi proposto que a irradiação com LASER sobre a dentina poderia substituir o condicionamento ácido, uma vez proporcionava características como ausência de smear layer e túbulos dentinários abertos. (VISURI et al., 1996; DOSTALOVÁ et al., 1998). Diversos autores (MARTíNEZ-INSUA et al., 2000; CEBALLOS et al., 2001; CEBALLOS et al., 2002; DE MUNCK et al., 2002; CORONA et al., 2003; DUNN et al., 2005; MANHÃES et al., 2005; OLIVEIRA et al., 2005; LEE et al., 2007; SOUZA-ZARONI et al., 2007; AMARAL et al., 2008; BRULAT et al., 2008; ESTEVES-OLIVEIRA et al., 2008; MALTA et al., 2008; TACHIBANA et al., 2008; TORRES et al., 2009; FLURY et al., 2011; ANSARI et al., 2012; YAMAN et al., 
2012) avaliaram, através de testes de infiltração marginal e testes de resistência de união, a adesão obtida pelos sistemas adesivos aplicados sobre a dentina "condicionada" com LASER. Os resultados obtidos não demonstraram melhor interação dos sistemas adesivos com a dentina "condicionada" com LASER. Foi observado que o LASER irradiado diretamente sobre a dentina não proporcionava um substrato receptivo aos procedimentos adesivos.

Outra técnica envolvendo a utilização do LASER foi proposta por Gonçalves, Araújo e Damião (1999), com a irradiação do LASER (Nd:YLF) (Fluoreto de Ítrio e Lítio dopado com íons Neodímio) sobre o sistema adesivo já aplicado em dentina, porém previamente à fotoativação. Os resultados demonstraram um aumento significativo da resistência de união, obtida em teste de cisalhamento. Segundo os autores a irradiação de LASER Nd:YLF sobre o sistema adesivo "criou um substrato mais resistente fisicamente e com uma maior afinidade química ao processo de adesão". Resultados favoráveis também foram obtidos irradiando-se LASER Nd:YAG (Granada de Ítrio e Alumínio, dopado com Neodímio) sobre sistema adesivo convencional de dois passos e convencional de passo único, previamente à fotoativação dos mesmos (FRANKE et al., 2006; MARIMOTO et al., 2012).

Apesar dos resultados promissores, a utilização destes tipos de LASER pode ser restrita. O LASER Nd:YLF utilizado por Gonçalves et al. (1999) foi um LASER experimental criado no Instituto de Estudos Avançados e Instituto de Pesquisas Energéticas e Nucleares (IEAv e IPEN, São José dos Campos, Brasil) e devido às suas grandes proporções, sua utilização é clinicamente inviável. $O$ aparelho de LASER Nd:YAG, assim como a maioria dos aparelhos de LASER de alta potência, possui proporções bem menores que o LASER Nd:YFL, com possiblidade de utilização clínica, no entanto, ainda continuam robustos e com custo elevado.

Uma alternativa consiste no LASER de Diodo, que apresenta custo e tamanho bastante reduzidos. Além disso este tipo de LASER pode apresentar variados comprimentos de onda, sendo um deles $(970 \mathrm{~nm})$ muito próximo ao comprimento de onda do LASER Nd:YAG (1064nm). Dessa forma, é possível que a interação do LASER de Diodo com os sistemas adesivos apresente também resultados favoráveis.

Além destes fatores, pouca informação está disponível na literatura comparando o efeito da irradiação de LASER sobre os diferentes grupos de sistemas adesivos existentes. Atualmente a odontologia conta com quatro grupos de 
sistemas adesivos (convencionais de três ou dois passos, e autocondicionantes de dois passos ou passo único), cada um com composição e consequentemente comportamento clínico e laboratorial diferentes (PASHLEY et al., 2011 ;VAN MEERBEEK et al., 2011), sujeitos a efeitos variados após a interação com os diferentes tipos de LASER.

Em busca de evidências do efeito da irradiação LASER sobre os diferentes grupos de sistemas adesivos, e também de uma alternativa mais compacta e com custo mais acessível, o objetivo deste estudo foi avaliar o efeito da irradiação do LASER de Diodo sobre a resistência de união de diferentes sistemas adesivos aplicados sobre a dentina humana. 

2 Revisão de Literatura 



\section{REVISÃO DE LITERATURA}

Para melhor compreensão, a revisão de literatura foi dividida em três tópicos: Adesão, LASER, e Influência do LASER na adesão em dentina.

\subsection{ADESÃO}

O desenvolvimento de materiais restauradores com a capacidade de se aderirem ao substrato dentário, através dos sistemas adesivos, revolucionou a odontologia restauradora durante o século XX. Devido a possibilidade de se realizar praticamente qualquer procedimento restaurador, independente da presença de retenção mecânica, a adesão permitiu o desenvolvimento de uma odontologia mais conservativa, alterando o conceito de "extensão para prevenção" para a filosofia altamente conservadora aceita atualmente (TYAS et al., 2000). Além disso, foi também devido à adesão que hoje é possível a realização de restaurações de dentes anteriores promovendo a estética com altos níveis de satisfação.

Buonocore (1955) deu o primeiro passo para obtenção de adesão à estrutura dental. O autor observou que restaurações de resina realizadas com condicionamento prévio do esmalte com ácido fosfórico a 85\% eram capazes de se aderir à esta estrutura. A adesão foi atribuída à maior área disponível para união criada pelo condicionamento ácido. Mais tarde Gwinnett e Matsui (1967) observaram através de microscopia óptica e eletrônica a formação de "tags" de adesivo, com profundidade variando de 10 a $25 \mu \mathrm{m}$, e atribuíram a adesão da resina ao esmalte à penetração e polimerização do adesivo nas micro-retenções criadas pelo condicionamento ácido. A eficácia da adesão em esmalte foi comprovada por Mertz-Fairhurst et al. (1998) num acompanhamento clínico (10 anos), em que restaurações de resinas compostas com margens em esmalte apresentaram performance longevidade clínica comparável às restaurações convencionais de amálgama. Atualmente a manutenção do esmalte periférico é considerado crucial para determinação de maior longevidade das restaurações de resina composta (PASHLEY et al., 2011).

Ao contrário das características favoráveis da adesão em esmalte, a adesão em dentina teve um desenvolvimento mais lento, e ainda apresenta deficiências. Brudevold, Buonocore e Wileman (1956) avaliaram a adesão em dentina com 
diversas resinas acrílicas, obtendo resultados desfavoráveis com praticamente todos os produtos. Observou-se no entanto que a resina Sevriton (Dentsply AG, Nova Iorque, EUA) apresentou comportamento superior devido a utilização de um primer (baseado em ácido glicofosfórico, ácido metacrilato e metilmetacrilato) que se polimerizava sobre a dentina úmida. Apesar do melhor resultado imediato a união se perdia em pouco tempo de contato com a água. Bowen (1965) desenvolveu um dispositivo para avaliar quantitativamente a adesão, através de sua resistência à tração, e o utilizou para investigar a ação de um copolímero baseado em $N$ phenylglycine e glycidyl methacrylate (NPA-GMA). Seus resultados foram favoráveis para os padrões da época, com valores de resistência de união em torno de 6 a 7 MPa (BOWEN, 1965a;1965b;1965c).

Alguns autores afirmavam que o acúmulo de debris constituído principalmente por fragmentos de dentina e biofilme, contendo saliva e restos de materiais orgânicos era capaz de comprometer a adesão à dentina (EICK et al., 1970). Brännström e Johnson (1974) sugeriram a utilização de soluções desmineralizadoras, com o objetivo de promover a limpeza dos túbulos dentinários e permitir melhor infiltração dos adesivos, no entanto, apenas Fusayama et al. (1979) observaram que o condicionamento ácido favorecia a adesão à dentina.

Os primeiros relatos de uma adesão eficiente à dentina (da ordem de $18 \mathrm{MPa}$ ) ocorreram após a proposição da utilização de monômeros resinosos contendo grupos hidrofílicos capazes de penetrar entre as fibrilas de colágeno desmineralizadas, formando a posteriormente denominada "camada híbrida" (NAKABAYASHI; KOJIMA; MASUHARA, 1982).

O conceito de camada híbrida, associada ao condicionamento ácido do esmalte consistem atualmente nos principais mecanismos de adesão às estruturas dentárias (PASHLEY et al., 2011). Desta forma, a técnica proposta para se obter a adesão de resinas compostas às estruturas dentárias consiste na utilização dos sistema adesivos. Atualmente os sistemas adesivos podem ser classificados em 4 grupos de acordo com o tratamento do debris ou lama dentinária (smear layer) e do número de passos (Quadro 1). 
Quadro 1: Descrição dos 4 grupos de sistemas adesivos utilizados atualmente.

\begin{tabular}{|c|c|}
\hline Sistema adesivo & Descrição do sistema \\
\hline $\begin{array}{l}\text { Convencional de três } \\
\text { passos (não } \\
\text { simplificado) }\end{array}$ & $\begin{array}{l}\text { O } 1^{\circ} \text { passo deste sistema consiste na aplicação do ácido fosfórico a } \\
37 \% \text { por } 15 \text { segundos, seguido de lavagem abundante, para criar } \\
\text { micro-retenções no esmalte e expor as fibrilas de colágeno na } \\
\text { dentina. } 02^{\circ} \text { passo inicia-se com a secagem controlada da dentina, } \\
\text { com o objetivo de remover o excesso de água, no entanto sem } \\
\text { causar o colapso das fibrilas de colágeno. Após a secagem é } \\
\text { aplicado monômero resinoso hidrofílico (primer) capaz de penetrar } \\
\text { nas fibrilas de colágeno úmidas, seguido da aplicação de um } \\
\text { adesivo hidrofóbico ( } 3^{\circ} \text { passo) que tem o objetivo de se unir tanto ao } \\
\text { primer, quanto à resina composta que será inserida na sequência. }\end{array}$ \\
\hline $\begin{array}{l}\text { Convencional de dois } \\
\text { passos (simplificado) }\end{array}$ & $\begin{array}{l}\text { Este sistema mantém a etapa de condicionamento do ácido do } \\
\text { esmalte e da dentina da mesma forma que o anterior, no entanto o } \\
2^{\circ} \text { e } 3^{\circ} \text { passo são unidos num único passo. }\end{array}$ \\
\hline $\begin{array}{l}\text { Autocondicionante de } \\
\text { dois passos (não } \\
\text { simplificado) }\end{array}$ & $\begin{array}{l}\text { Neste sistema a etapa de condicionamento ácido foi unida ao } 2^{\circ} \\
\text { passo do adesivo convencional de três passos, com o } \\
\text { desenvolvimento de um primer acídico, capaz de expor e ao mesmo } \\
\text { tempo se infiltrar nas fibrilas de colágeno, formando a camada } \\
\text { híbrida. Em seguida manteve-se a aplicação do adesivo hidrofóbico. }\end{array}$ \\
\hline $\begin{array}{l}\text { Autocondicionante de } \\
\text { passo único } \\
\text { (simplificado) }\end{array}$ & $\begin{array}{l}\text { Neste sistema todos os passos foram unidos em um único, através } \\
\text { do desenvolvimento de um agente hidrofílico e acídico, ainda com } \\
\text { propriedades adesivas. }\end{array}$ \\
\hline
\end{tabular}

Apesar das versões simplificadas do sistema adesivo reduzirem os passos clínicos e o tempo de trabalho, seus resultados laboratoriais e clínicos a longo prazo nem sempre são satisfatórios. As simplificações decorrentes da união do primer com o adesivo hidrofóbico não obtiveram bons resultados, principalmente nos sistemas de passo único. Segundo Carvalho (2004) estes adesivos comportam-se como membranas permeáveis capazes de atrair água da dentina para interface adesivo / resina composta, criando bolhas e comprometendo a união da resina com o adesivo. Posteriormente, a água do meio externo também ganha acesso à essa região e colabora para a degradação da interface adesiva (TAY et al., 2002). Evidências da passagem de água foram observadas por TAY; PASHLEY; YOSHIYAMA, 2002 e denominadas nanoinfiltração.

Por outro lado, a associação da etapa de condicionamento ácido à etapa de hibridização da dentina, criando os sistemas adesivos autocondicionantes de 2 passos, determinou resultados mais satisfatórios. Os problemas relacionados anteriormente não acontecem devido a presença da camada de adesivo hidrofóbico que impermeabiliza o primer hidrofílico, retardando a nanoinfiltração e reduzindo a permeabilidade (CARVALHO, 2004). Além disso, neste sistema a técnica torna-se 
mais simplificada, uma vez que a etapa mais crítica dos adesivos convencionais, que consiste no difícil e sensível controle da umidade dentinária, não é necessária. O primer ácido pode ser aplicado sobre a dentina seca uma vez que não acontece o colapso das fibrilas de colágeno que estão protegidas pela hidroxiapatita, e são hibridizadas no momento em que ocorre a penetração do adesivo (GORDAN et al., 1997). Outra vantagem de algumas marcas comerciais de sistemas autocondicionantes de dois passos consiste na presença do MDP, (10metacriloxidecil dihidrogenio fosfato) uma substância capaz de se ligar quimicamente ao cálcio, formando fosfato de cálcio, aumentando ainda mais a efetividade da adesão destes sistemas (VAN MEERBEEK et al., 2011).

Em suma, os melhores resultados atualmente são obtidos pelos sistemas adesivos convencionais de três passos e sistemas adesivos autocondicionantes de dois passos (DE MUNCK et al., 2012). Apesar disso, mesmo nestes sistemas deficiências ainda estão evidentes, principalmente quando as margens da restauração situam-se em dentina. Segundo (SPENCER et al., 2010), a adesão em dentina ainda representa a fraca ligação entre a resina composta e o dente, principalmente devido à degradação hidrolítica da camada híbrida. Estudos clínicos avaliaram a longevidade de restaurações extensas de resina composta, com término em dentina, e obtiveram resultados insatisfatórios (MJOR; DAHL; MOORHEAD, 2002; SONCINI et al., 2007).

Outro problema enfrentado pelos sistemas adesivos consiste na degradação da camada híbrida causada pela ação de enzimas proteolíticas, como as metaloproteinases e as catepsinas, capazes de degradar as fibrilas de colágeno expostas pelo ácido fosfórico na interface adesiva. Estudos tem demonstrado que a aplicação de solução de clorexidina a 2 ou $0,2 \%$, por 30 a 60 segundos, é capaz de inibir a ação destas enzimas, favorecendo a obtenção de uma adesão em dentina mais duradoura, no entanto, apenas capaz de postergar a degradação da camada híbrida (PASHLEY et al., 2004; HEBLING et al., 2005; CARRILHO et al., 2007; BRESCHI et al., 2008; TJÄDERHANE et al., 2013).

Assim como o efeito inibidor da clorexidina, diariamente novas soluções são propostas para favorecer a adesão em dentina. No entanto, a realização de investigações clínicas para cada nova variável idealizada requer tempo e custo muitas vezes não disponível. Por este motivo, testes laboratoriais foram desenvolvidos com o objetivo de facilitar a comparação entre novos materiais e 
técnicas, além de permitir certa previsão de seu comportamento clínico. Bowen (1965) foi um dos precursores dos testes laboratoriais de adesão. Descreveu um ensaio laboratorial capaz de medir a resistência à tração das resinas compostas ao dente, obtendo valores em $\mathrm{kg} / \mathrm{cm}^{2}$. Retief (1991) contribuiu para a padronização do teste de tração, no entanto, Pashley et al. (1995) já observava o grande número de variáveis que poderiam influenciar nos testes de adesão, sendo uma das mais importantes o tamanho da área a ser testada. Segundo o autor, quanto menor a área testada, maior a resistência de união em MPa, devido à menor quantidade de falhas coesivas em dentina. Perinka et al. (1992) e Erickson (1989) obtiveram resultados superiores a $80 \%$ de fratura coesiva em dentina ao utilizar uma área de $23,8 \mathrm{~mm}^{2} \mathrm{e}$ $12,3 \mathrm{~mm}^{2}$ respectivamente.

Sano et al. (1994), com objetivo de reduzir estas falhas, propôs o teste de microtração, baseado no corte do dente numa máquina de corte digital, formando palitos com área de secção transversal de $2 \mathrm{~mm}^{2}$. O autor obteve excelentes resultados, com praticamente nenhuma falha coesiva em dentina quando a área testada foi inferior a $2 \mathrm{~mm}^{2}$. A partir deste estudo, e da revisão dos testes de adesão realizada por Pashley et al. (1995), o teste de microtração tornou-se o principal teste de adesão utilizado mundialmente. Cerca de $60 \%$ dos estudos laboratoriais nesta área utilizam o teste de microtração para avaliar a resistência de união dos diferentes materiais e técnicas lançados recentemente (VAN MEERBEEK et al, 2010).

Além de ser o teste laboratorial mais aceito pela comunidade científica, Van Meerbeek et al. (2010) observaram que os testes de adesão apresentam alguma correlação com resultados clínicos, principalmente quando o envelhecimento é utilizado. Portanto, atualmente considera-se o teste de microtração uma das avaliações laboratoriais que apresenta maior evidência científica para investigar os novos materiais e técnicas (DE MUNCK et al., 2012). 


\subsection{LASER}

A palavra LASER é um acrônimo do inglês Light Amplification by Stimulated Emission of Radiation, e significa a Amplificação da Luz através de Emissão Estimulada de Radiação. Para compreender o mecanismo de amplificação da luz, bem como as propriedades da luz LASER, é necessário primeiramente entender os conceitos de emissão espontânea e emissão estimulada desenvolvidos pelo físico Albert Einstein (TIPLER e MOSCA, 2009).

\section{- Emissão Espontânea:}

A Emissão Espontânea é um fenômeno decorrente da liberação de energia, na forma de radiação (fóton), de um átomo ou molécula excitado (estado metaestável) que regride espontaneamente para seu estado de menor energia (estado fundamental) (Figura 1). Este fenômeno é mais bem visualizado em materiais que apresentam uma longa vida no estado metaestável, e portanto emite fótons por uma maior quantidade de tempo. Empiricamente são conhecidos como materiais fosforescentes.

A diferença de energia do estado metaestável e do estado fundamental de cada átomo ou molécula determina o comprimento de onda do fóton emitido.

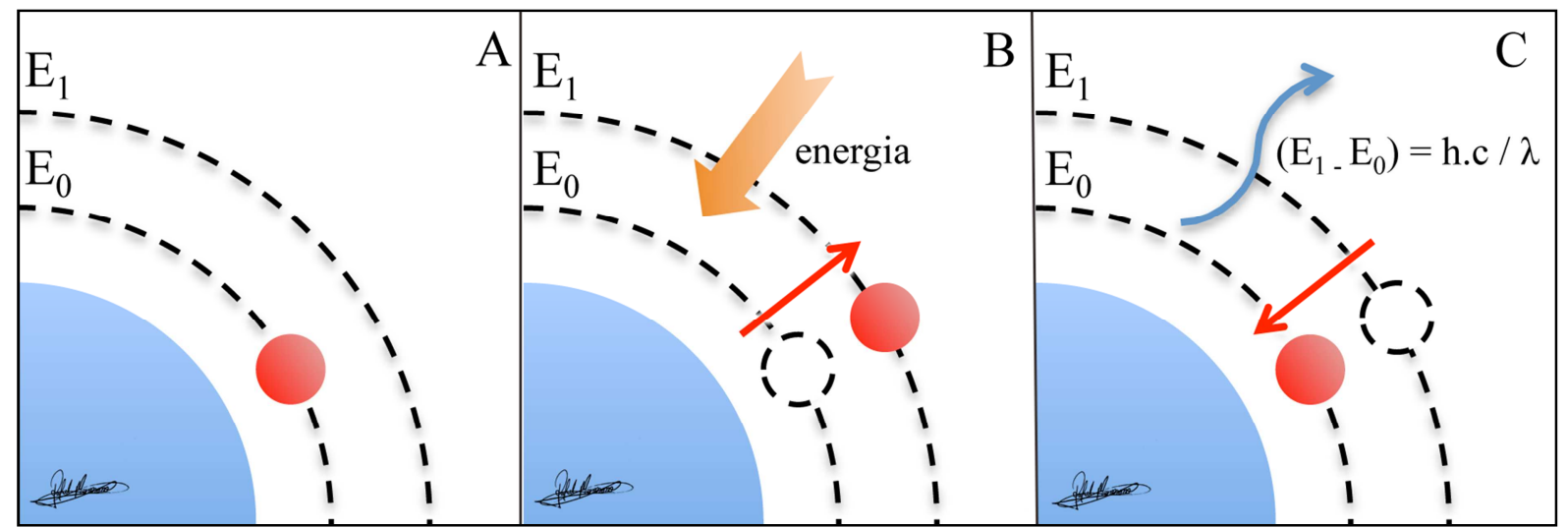

Figura 1: O processo de emissão espontânea acontece quando um átomo ou molécula em seu estado de menor energia ou estado fundamental (A) recebe uma certa quantidade de energia, passando para um estado de semi-estabilidade mais energético, denominado estado metaestável (B). O átomo no estado metaestável regride espontaneamente para seu estado fundamental, liberando um fóton, cuja energia determina seu comprimento de onda (C). Adaptado de Tipler e Mosca (2009). $\mathrm{E}_{1}=$ Energia do estado mais energético; $\mathrm{E}_{0}=$ Energia do estado fundamental; $\mathrm{h}=$ constante de Planck; $\mathrm{c}=$ velocidade da luz; $\lambda=$ comprimento de onda 
- Emissão Estimulada:

O fenômeno da emissão estimulada acontece quando um fóton colide com um átomo ou molécula que já apresenta-se num estado metaestável. Se o fóton colidente apresentar energia equivalente à diferença de energia do estado metaestável e do estado fundamental, este fóton é capaz de estimular o átomo metaestável a emitir um fóton na mesma direção e em fase com o fóton incidente (Figura 2).

Num sistema com mais átomos ou moléculas semelhantes e excitados, os fótons emitidos podem estimular a emissão de fótons adicionais, desencadeando um processo de amplificação da luz, determinando um feixe coerente e de comprimento de onda definido.

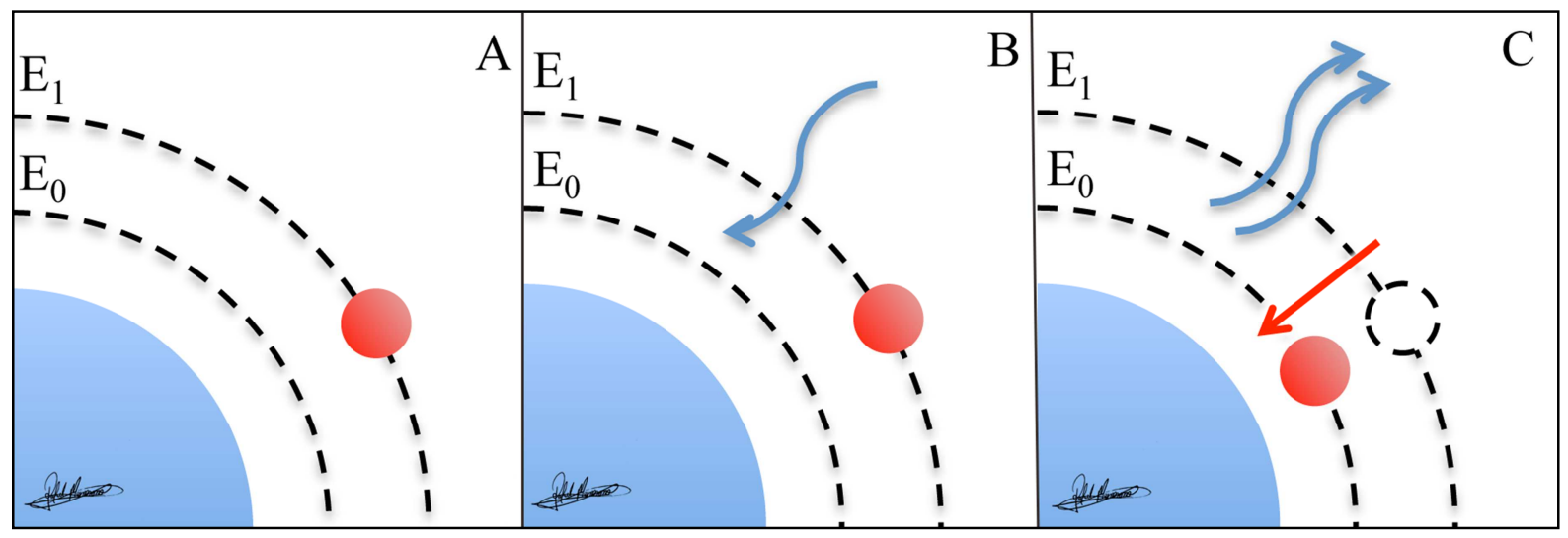

Figura 2: O processo de emissão estimulada acontece quando um átomo ou molécula já se apresenta no estado metaestável $(A)$ e recebe um fóton com quantidade de energia exatamente igual a $E_{1}-E_{0}$ (B). Esta energia causa um distúrbio no átomo, estimulando-o a regredir para o estado fundamental e liberar outro fóton, em fase e de mesma energia que o fóton incidente (C). Adaptado de Tipler e Mosca (2009).

Baseado nestes conceitos, Maiman (1960) desenvolveu o primeiro aparelho de luz LASER, que consistia numa barra de rubi, com uma das extremidades completamente espelhada, e a outra refletindo $85 \%$ da luz, envolta por um tubo helicoidal que emite um espectro amplo de luz (Figura 3). Esta luz de amplo espectro é responsável por excitar os átomos do cristal de rubi, tornando-os metaestáveis (fenômeno chamado de inversão da população). Através de emissão espontânea, fótons são emitidos com a quantidade de energia exata para dar início ao processo de emissão estimulada, devido ao alto grau de pureza dos cristais, que 
apresentam moléculas muito semelhantes. Esta sequência de eventos proporciona a amplificação da luz, que é totalmente refletida em uma das faces, e na outra é liberada, determinando a saída de um feixe de luz coerente e com comprimento de onda definido (no caso do laser de rubi o comprimento de onda é de $693,4 \mathrm{~nm}$, e determina a cor vermelha).

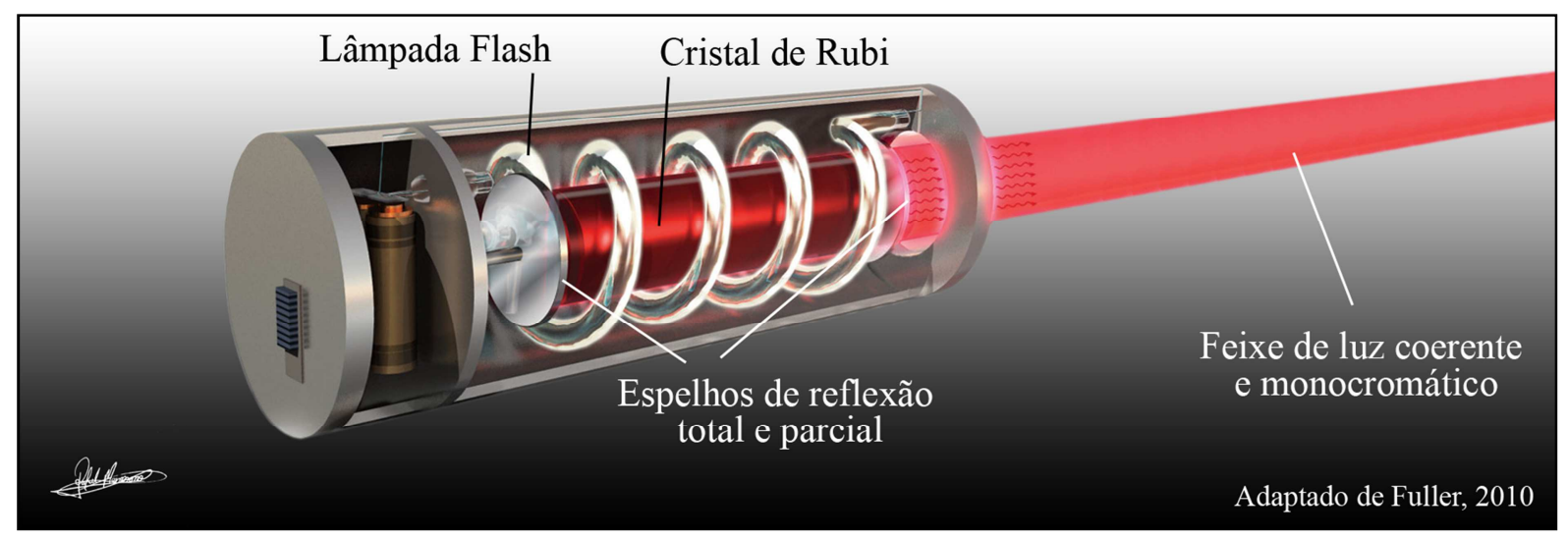

Figura 3: O LASER de Rubi consiste num cristal de rubi, com uma das extremidades completamente espelhada, e a outra refletindo $85 \%$ da luz, envolta por um tubo helicoidal que emite radiação* num espectro amplo. Esta radiação fornece energia para causar a inversão da população (maior quantidade de átomos no estado metaestável) e dar início aos processos de emissão espontânea e emissão* estimulada*, que vão determinar amplificação* da luz*, resultando na propagação de um feixe de luz coerente e monocromático, com comprimento de onda definido.

* Estas palavras foram o acrônimo LASER (Light Amplification by Stimulated Emission of Radiation).

Posteriormente foram desenvolvidos outros tipos de LASERs variando-se o meio ativo que poderia ser líquido, sólido ou gasoso, determinando diferentes comprimentos de onda (Quadro 2) capazes de promover efeitos distintos sobre os tecidos irradiados.

Quadro 2: Outros tipos de LASER com comprimentos de onda distintos.

\begin{tabular}{|ccc|}
\hline Autores & Tipo de Laser & Comprimento de onda (nm) \\
\hline Javan et al, 1961 & HeNe & $543-633$ \\
Hall et al, 1962 & Diodo & 842 (pode variar) \\
Patel et al, 1964 & $\mathrm{CO}_{2}$ & 10600 \\
Geusic e Smith, 1964 & Nd:YAG & 1064 \\
Hibst e Keller, 1989 & Er:YAG & 2940 \\
\hline
\end{tabular}

Fonte: PINHEIRO, BRUGNERA e ZANIN, 2010 
Uma tecnologia que nos chama atenção é a do LASER de Diodo. A inversão da população para gerar moléculas metaestáveis não é estimulada por radiação, como nos outros LASERs, mas através de um semicondutor, que utiliza diretamente a energia elétrica para estimular as moléculas. O semicondutor é um material de custo mais acessível, e de proporções menores, o que resulta em aparelhos de LASER de Diodo com custo reduzido e altamente portáteis. Além disso, alterando-se o meio ativo das junções p-n do próprio semicondutor é possível variar o comprimento de onda destes aparelhos. Devido à estas características, os LASERs de Diodo são os mais utilizados em nosso cotidiano: está presente no leitor de CDs e DVDs, em impressoras e escâneres, ponteiras e transmissão de dados por fibra ótica.

O conhecimento do comprimento de onda do LASER é de fundamental importância para definir quais serão os efeitos da irradiação nos tecidos, uma vez que para cada comprimento de onda, cada tecido ou substância pode ter maior ou menor absorção da luz, definindo a quantidade de interação com a luz que estes componentes apresentarão. Apesar disso, o comprimento de onda não é o único parâmetro que deve ser observado. O conhecimento de outros parâmetros, assim como na farmacologia, é imprescindível para determinar a cura e não o veneno. $\mathrm{Na}$ sequência estão listados alguns parâmetros de conhecimento necessário para a utilização do LASER.

- Energia por pulso (Ep): A energia é o parâmetro base da irradiação LASER, e se refere à quantidade de energia, em Joules $(\mathrm{J})$, existente em um pulso.

- Frequência (F): Determina a quantidade de pulsos emitidos em um segundo. Sua grandeza é quantificada em Hertz $(\mathrm{Hz})$ e equivale $\mathrm{a} \mathrm{s}^{-1}$.

- Energia Total (Et): É a quantidade total de energia irradiada, calculada através da multiplicação da energia por pulso, pela frequência e pelo tempo total (t) de irradiação $(E t=E p \times F \times t)$.

- Potência (P): É dada em Watts (W), e equivale a Joules por segundo (J/s), e significa a quantidade de energia irradiada, numa determinada quantidade de tempo. Este é um dos parâmetros a serem configurados nos aparelhos de LASER, no entanto, para discussão científica e criação de uma padronização, o fornecimento de outros parâmetros se faz necessário, uma vez que é possível causar efeitos muito diferentes numa mesma potência. Seu cálculo é baseado na quantidade de 
energia total utilizada, dividido pelo tempo de irradiação $(P=E t / t)$. Pode ainda ser calculada através da multiplicação da energia por pulso pela frequência $(P=E p \times F)$.

- Densidade de Potência (DP): é um dos parâmetros mais importantes para a padronização dos experimentos, uma vez que define a penetração da irradiação LASER no tecido. É baseada na quantidade de energia fornecida, num determinado tempo, dividido pela área (a) da secção transversal do feixe de luz ( $D P=P / a)$. (Figura 4).

- Área da secção transversal do feixe de luz (a): tem papel imprescindível na determinação da densidade de potência, e para obter este valor é necessário conhecer a espessura da fibra ótica.

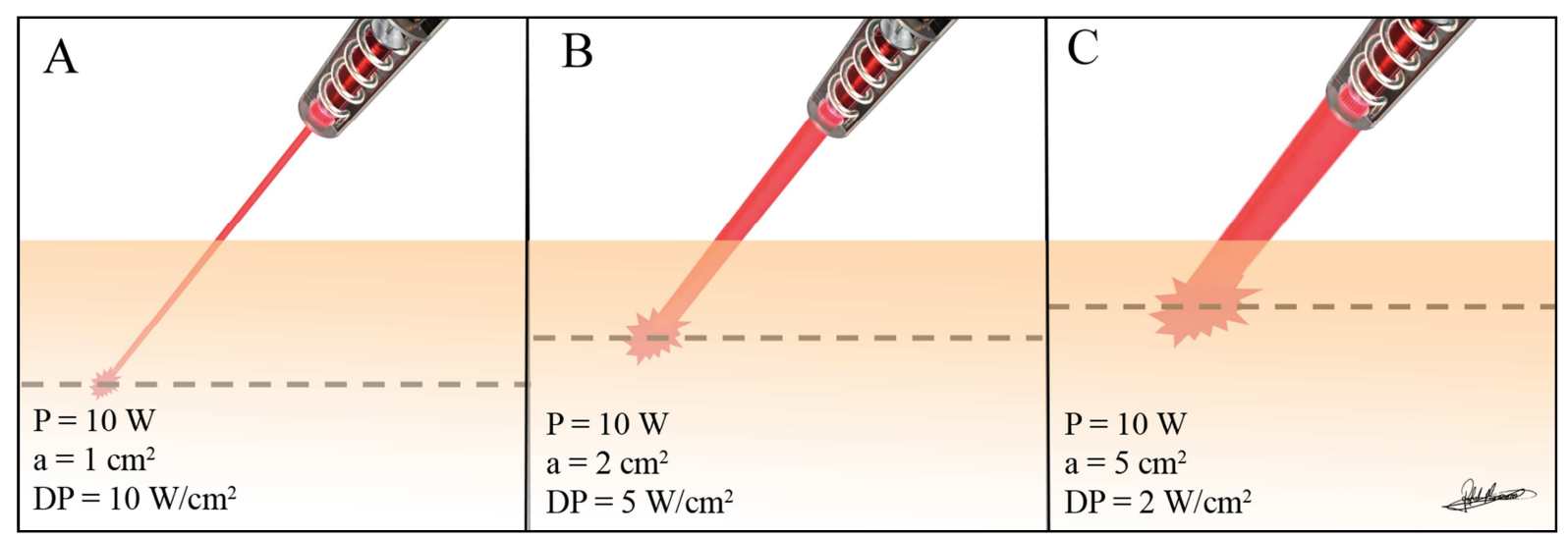

Figura 4: Considere que para as três situações ( $A, B$ e $C$ ) a potência $(P)$, ou seja, a quantidade de energia irradiada por segundo, seja a mesma, no entanto, a área da secção transversal do feixe de luz (a) é alterada. Observe que quanto menor a espessura do feixe, maior é a densidade de potência (DP), e maior a capacidade de penetração da luz (A), enquanto num feixe de luz mais espesso a penetração, assim como a densidade de potência são menores (C).

- Distância da ponta ao alvo: apesar do feixe de luz LASER ser coerente, quando levado através de uma fibra ótica parte desta propriedade é perdida, ou seja, a partir do momento que a luz sai da fibra ela apresenta uma pequena divergência. Esta característica determina uma amplificação da área da secção transversal do feixe de luz (a) a medida que aumentamos a distância da ponta ativa ao alvo, causando consequentemente uma queda na Densidade de Potência (DP).

- Área a ser irradiada (A): também em situações de irradiação por varredura, é fundamental se determinar a área total a ser irradiada, a fim de se obter o valor da densidade de energia. 
- Densidade de Energia (DE): A densidade de energia é definida pela quantidade de energia irradiada numa determinada área $\left(\mathrm{J} / \mathrm{cm}^{2}\right)$, e é calculada pela divisão da energia total pela área irradiada ( $E t / A$ ). Este parâmetro é também essencial para a discussão dos trabalhos que utilizam o LASER, principalmente quando a irradiação é realizada em forma de varredura. Sua padronização evita o viés da diferença causada por exemplo, por uma irradiação com energia total de 1000J irradiada sobre uma área de $1 \mathrm{~cm}^{2}$, com uma irradiação com a mesma quantidade de energia, mas numa área de $50 \mathrm{~cm}^{2}$. A concentração de energia (densidade de energia) é muito maior na área de $1 \mathrm{~cm}^{2}$.

O conhecimento dos parâmetros e propriedades do LASER contribuíram para grandes avanços na indústria, na medicina e também na odontologia. Na dentística a tecnologia LASER foi introduzida em meados da década de 60, por Stern e Sogannaes (1964), ao irradiarem o LASER de Rubi sobre esmalte e dentina. Os autores observaram uma redução da permeabilidade da dentina e desmineralização do esmalte, no entanto, foi considerado de alto risco à polpa dentária devido ao calor gerado pela irradiação. Posteriormente observou-se que alterando o comprimento de onda e outros parâmetros, como a energia por pulso e a frequência, era possível a utilização do LASER sobre a estrutura dentária com mínima variação da temperatura, muito próxima da variação causada pela turbina de alta rotação, (RAUCCI-NETO et al., 2007).

Observado menor risco em relação ao aquecimento intracâmara pulpar, a tecnologia LASER foi empregada em outras funções. Através dos conceitos de emissão espontânea e fluorescência, foi lançado, em 1998, o DIAGNOdent (Kavo, Biberach, Alemanha) que consiste em um aparelho que utiliza fonte de luz LASER de Diodo, com comprimento de onda de $655 \mathrm{~nm}$ (cor vermelha). Ao irradiar esta luz sobre o tecido cariado, este responde emitindo luz em comprimentos de onda acima de $680 \mathrm{~nm}$. Através de um filtro que não permite a passagem de luz com comprimento de onda inferior a $680 \mathrm{~nm}$, o aparelho DIAGNOdent se sensibiliza e calcula a quantidade de tecido cariado presente de acordo com a quantidade de luz que recebe, numa escala de 0 a 99 (PINHEIRO, BRUGNERA e ZANIN, 2010). Lussi et al $(1999 ; 2001)$ avaliaram a sensibilidade e a especificidade deste aparelho em relação ao diagnóstico de lesões cariosas, e afirmaram que trata-se de uma ferramenta valiosa para o monitoramento longitudinal de lesões cariosas, e um 
importante exame complementar quando dúvidas permanecem após a inspeção visual.

Outra aplicação do LASER de Diodo (de $830 \mathrm{~nm}$ ) está relacionada com o clareamento dental. Sua associação com Diodos Emissores de Luz (LED) com comprimento de onda em torno de $470 \mathrm{~nm}$ reduz o tempo de clareamento através a potencialização da liberação do oxigênio (LUK, TAM e HUBERT, 2004). Mondelli et al. (2011) confirmaram em estudo clínico que a associação do gel clareador com a ativação com luz reduz o tempo necessário para o clareamento.

Ademais a tecnologia LASER também está presente na odontologia preventiva. Estudos demonstraram que o LASER Nd:YAG é capaz de aumentar a resistência do esmalte à desmineralização e aumentar a absorção de flúor (BAHAR e TAGOMORI, 1994), causando um efeito sinérgico na inibição do desenvolvimento de lesões cariosas, quando utilizado em conjunto com verniz fluoretado (HUANG et al., 2001). Mais recentemente, Correa-Afonso et al. (2012) observaram que 0 LASER de $\mathrm{CO}_{2}(10600 \mathrm{~nm})$ apresentou os resultados mais favoráveis no aumento da resistência do esmalte à desmineralização pela ciclagem de $\mathrm{pH}$.

A remoção de tecido cariado e o preparo de cavidades também pode ser realizado com segurança através da irradiação com LASER Er:YAG (HIBST e KELLER, 1989). A emissão de luz deste LASER acontece no comprimento de onda de 2940nm, que é fortemente absorvido pela água presente nos tecidos. Como resultado observa-se um rápido aquecimento altamente localizado capaz de provocar microexplosões no esmalte e dentina, determinando o processo conhecido como Ablação, responsável pela remoção de tecido dentário. A grande vantagem deste tipo de preparo cavitário consiste na redução do desconforto causado pela turbina de alta rotação, o que determina uma preferência de $82 \%$ dos pacientes pelo tratamento com LASER (KELLER et al, 1998).

Em virtude da ampla utilização das resinas compostas como material restaurador, grande interesse foi gerado na morfologia do substrato dentário irradiado com LASER. Moritz et al. (1996) avaliou microscopicamente, e através de teste de resistência de união, diferentes tipos de condicionamento do esmalte, incluindo em seus estudos os LASERs Nd:YAG, $\mathrm{CO}_{2}$ e Er:YAG. Seus resultados em esmalte foram favoráveis e despertaram grande interesse no efeito causado pela irradiação LASER sobre a adesão em dentina. 
2.3. INFLUÊNCIA DA IRRADIAÇÃO LASER NA ADESÃO À DENTINA

O interesse por uma adesão mais eficiente à dentina, associado ao conhecimento morfológico deste substrato irradiado com alguns tipos de LASER, apresentando uma superfície micro-retentiva, túbulos dentinários abertos e ausência de smear layer (VISURI et al., 1996; DOSTALOVÁ et al., 1998), incentivaram intensa investigação em busca da qualidade da adesão obtida sobre este substrato.

Um dos artigos mais citados na área consiste no trabalho de Ceballos et al. (2001). Os autores compararam a infiltração marginal de cavidades classe $V$, após imersão em fucsina básica $(0,5 \%)$, de dentes que sofreram condicionamento com ácido fosfórico a 35\% (controle), com dentes condicionados através da irradiação com LASER Er:YAG. Foi observado maior infiltração marginal da margem oclusal nos espécimes irradiados com LASER Er:YAG. Na margem gengival tanto a irradiação com LASER quanto o condicionamento ácido determinaram grande quantidade de infiltração marginal, no entanto sem diferença entre os tratamentos. Os autores não consideraram a irradiação com LASER Er:YAG uma alternativa válida para o condicionamento da dentina para restaurações de resina composta, apesar das características aparentemente vantajosas para adesão que este substrato apresenta. Outros estudos avaliando a infiltração marginal após o condicionamento com LASER Er:YAG corroboram com os achados de Ceballos. Independente dos parâmetros utilizados, em nenhum destes estudos foi observada menor infiltração marginal que o grupo controle (CORONA et al., 2003; ESTEVESOLIVEIRA et al., 2008; YAMAN et al., 2012).

De Munck et al (2002), através do teste de microtração, avaliaram a resistência de união de adesivo convencional de três passos (OptiBond FL, Kerr, EUA) e autocondicionante de dois passos (Clearfil SE, Kuraray, Japão) aplicados sobre cavidade preparada com LASER Er:YAG utilizando-se $120 \mathrm{~mJ}$ de energia por pulso, frequência de $10 \mathrm{~Hz}$ e uma ponta de safira com extremidade de $0,8 \mathrm{~mm}$ de diâmetro, e condicionada com $80 \mathrm{~mJ}$ de energia por pulso e frequência de $10 \mathrm{~Hz}$ (o tempo de irradiação, bem como a área irradiada e consequentemente a densidade de energia, não foram informados). Os resultados obtidos foram altamente significantes, com queda superior à $50 \%$ da resistência de união obtida com tratamento convencional (controle). Segundo os autores, cavidades preparadas com 
LASER Er:YAG apresentam-se menos receptivas para procedimentos adesivos do que cavidades preparadas com brocas e pontas convencionais.

Manhães et al., 2005; Oliveira et al., 2005; Souza-Zaroni et al., 2007; Lee at al., 2007; Amaral et al., 2008; Malta et al., 2008; Tachibana et al., 2008 e Flury et al., 2011 também compararam a resistência de união da dentina tratada com LASER Er:YAG através do teste de microtração. Alguns autores observaram resistência de união similar ao tratamento convencional, principalmente quando após o preparo cavitário o ácido fosfórico foi utilizado para o condicionamento da dentina, favorecendo a utilização do LASER Er:YAG para o preparo cavitário. No entanto, nenhum destes autores observou uma aumento da resistência de união que justifique a utilização do LASER Er:YAG com o objetivo de aumentar ou melhorar a qualidade da adesão entre a resina composta e a dentina.

Diversas investigações utilizando o LASER Er:YAG para condicionamento da dentina basearam-se também em testes de resistência de união, utilizando não só testes de microtração, mas também testes de tração (MARTíNEZ-INSUA et al., 2000), cisalhamento (CEBALLOS et al., 2002; BRULAT et al., 2008; TORRES et al., 2009) e microcisalhamento (DUNN et al., 2005; ANSARI et al., 2012). Apesar da diferença no tipo de teste, os resultados foram similares aos anteriores: 0 condicionamento da dentina com LASER Er:YAG não influenciou positivamente a resistência de união de forma que justifique sua utilização prévia apenas para promoção de uma adesão mais confiável ao substrato dentinário.

Por outro lado, utilizando LASER no comprimento de onda de 1064nm, Gonçalves, Araújo e Damião (1999) propuseram uma variação da técnica. Os autores irradiaram com LASER Nd:YFL (densidade de energia de $1,31 \mathrm{~J} / \mathrm{cm}^{2}$, frequência de $0,3 \mathrm{~Hz}$, energia por pulso de $250 \mathrm{~mJ}$ e diâmetro do feixe de $5 \mathrm{~mm}$ ) a superfície da dentina após o tratamento com ácido fosfórico a 37\% e aplicação do sistema adesivo convencional de três passos (Adper ${ }^{\text {TM }}$ Scothbond Multi-Purpose Plus, 3M ESPE, St Paul, EUA), mas antes de sua fotoativação. Em avaliação realizada através do teste de cisalhamento, foram obtidos resultados promissores, com aumento significativo da resistência de união. Segundo os autores, a irradiação do LASER Nd:YFL sobre o sistema adesivo favoreceu a criação de um substrato mais resistente fisicamente, e mais susceptível à adesão.

Matos et al., 2000, irradiando LASER Nd:YAG após a aplicação de sistema adesivo autocondicionante de dois passos (Clearfil ${ }^{\mathrm{TM}}$ Liner Bond, Kuraray, Japão), 
mas também antes de sua fotoativação, obteve resultados favoráveis em teste de tração. Foi utilizado $0,6 \mathrm{~W}$ de potência, com frequência de $15 \mathrm{~Hz}$, com $40 \mathrm{~mJ}$ de energia por pulso, e uma fibra ótica de $320 \mu \mathrm{m}$ de diâmetro. A irradiação foi realizada em forma de varredura, a $1 \mathrm{~mm}$ de distância do espécime, durante 30s (a área, e consequentemente a densidade de energia não foram fornecidos). Segundo os autores, o melhor momento para realizar a irradiação com LASER é depois da aplicação do sistema adesivo.

Franke et al., 2006 avaliaram a técnica de irradiação do LASER Nd:YAG após a aplicação do sistema adesivo através do teste de microtração. Os autores avaliaram ainda o efeito da variação da densidade de energia aplicada sobre a área irradiada, e observaram que a irradiação com $5 \mathrm{~J} / \mathrm{cm}^{2}$ era capaz de aumentar a resistência de união de um adesivo convencional de dois passos (Adper ${ }^{\mathrm{TM}}$ SingleBond 2, 3M ESPE, St Paul, EUA), enquanto valores de 10 e $50 \mathrm{~J} / \mathrm{cm}^{2}$ não causavam alterações significativas nos valores de resistência de união. Através de microscopia eletrônica de varredura os autores observaram uma melhor penetração do sistema adesivo na dentina quando o LASER foi utilizado.

Malta et al., 2008 avaliaram tanto o efeito do preparo cavitário realizado com LASER Er:YAG, como o efeito da irradiação do sistema adesivo com LASER $\mathrm{Nd}: Y A G$ antes da fotoativação do sistema adesivo, através de teste de microtração. Quanto ao preparo cavitário com LASER Er:YAG, os resultados foram similares aos de De Munck, et al. (2002), ou seja, houve redução significativa da resistência de união. Quanto a irradiação realizada sobre sistema adesivo, os autores não obtiveram resultados favoráveis, com valores de resistência de união semelhante aos grupos controle.

Mais recentemente, Marimoto et al. (2012) avaliaram a resistência de união de sistemas adesivos convencional de 2 passos (Adper ${ }^{\mathrm{TM}}$ SingleBond 2, 3M ESPE, EUA), e autocondicionante de passo único (Xeno III, Dentsply De Trey GmbH D, Germany) irradiados com LASER Nd:YAG após a sua aplicação, mas antes de sua fotoativação. Os autores observaram, através de teste de cisalhamento, que a resistência de união à dentina de ambos os adesivos aumentou significativamente.

Observa-se a partir destes estudos que algumas combinações de parâmetros do LASER associados a alguns tipos de sistemas adesivos resultam em valores superiores de resistência de união. No entanto, não existem evidências na literatura 
comparando o efeito da irradiação com LASER sobre os diferentes grupos de sistemas adesivos.

Ademais, apesar dos resultados promissores obtidos pelo LASER Nd:YAG, sua utilização para melhorar propriedades da adesão à dentina pode encontrar alguma resistência devido ao alto custo do aparelho, bem como seu tamanho robusto. Uma alternativa a ser avaliada consiste no LASER de Diodo, que devido à utilização de semicondutores, resulta num aparelho mais portátil e com custo reduzido (Figura 5), além de apresentar comprimento de onda (970nm) muito próximo ao do LASER Nd:YAG, e capacidade de simular os demais parâmetros utilizados.

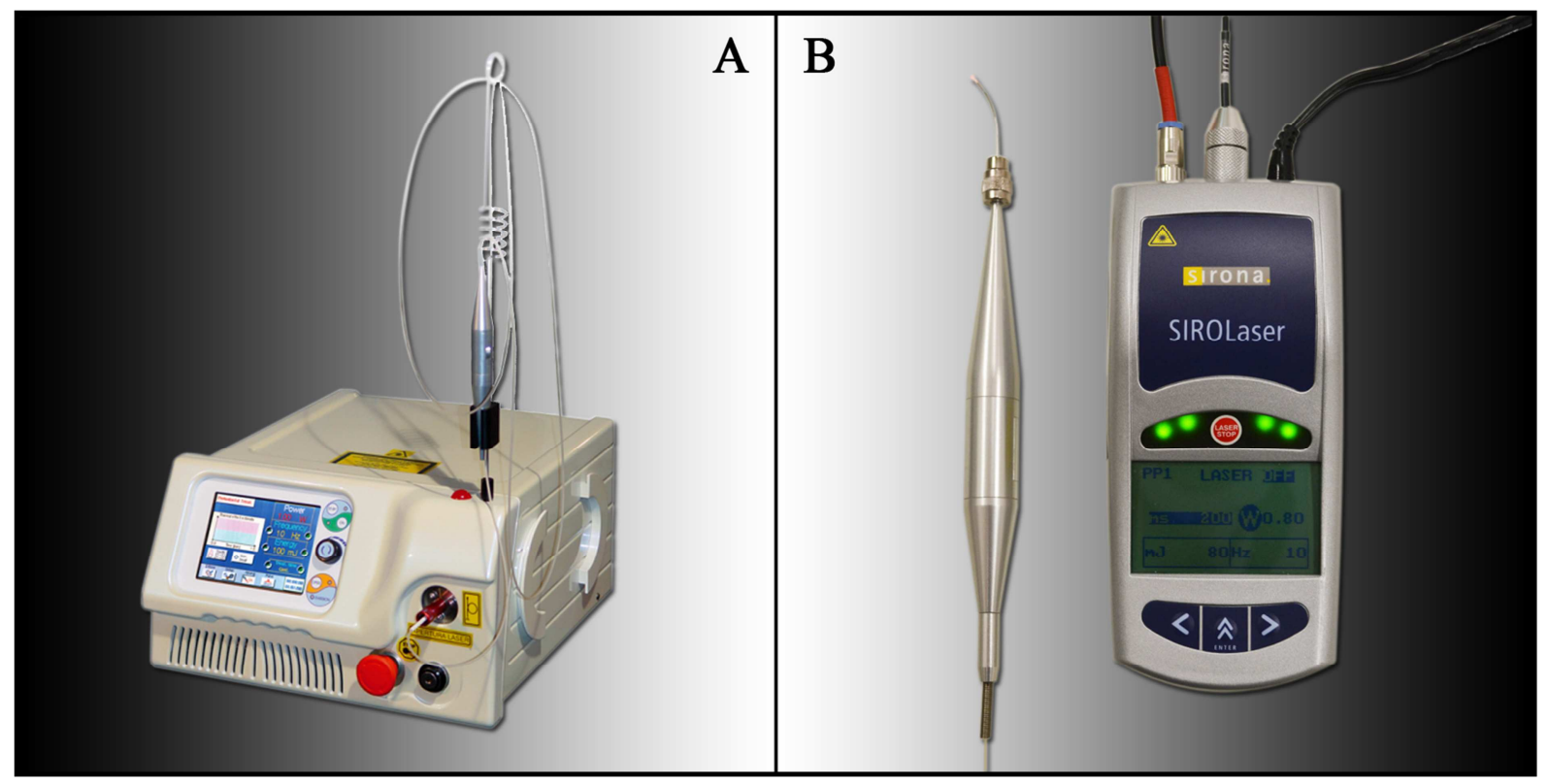

Figura 5: A) Exemplo de LASER Nd:YAG (Smartfile, Deka, Calenzano, Itália): dimensões de $20 \times 37 \times 39 \mathrm{~cm}, 13 \mathrm{Kg}$, custo em torno de $\mathrm{R} \$ 100.000,00$. B) LASER de Diodo (SiroLaser, Sirona Dental Systems, Benshein, Alemanha): dimensões de $8,7 \times 5,4 \times 19 \mathrm{~cm}, 450 \mathrm{~g}$ e custo em torno de $\mathrm{R} \$ 15.000,00$. 
3 Proposição 

3 PROPOSIÇÃO

Este estudo se propôs a avaliar, através do teste de microtração, a resistência de união à dentina de quatro grupo de sistemas adesivos irradiados ou não com LASER de Diodo.

Baseado na proposição, foram testadas as seguintes hipóteses nulas:

1. Não existe diferença na resistência de união entre os diferentes sistemas adesivos

2. Não existe diferença na resistência de união após a irradiação com LASER de Diodo 

4 Material e Métodos 



\section{MATERIAL E MÉTODOS}

\subsection{DELINEAMENTO EXPERIMENTAL}

O presente estudo in vitro foi fatorial $2 \times 4$ onde os fatores de variação foram: sistemas adesivos em 4 níveis (Quadro 3 e 4) e irradiação com laser em 2 níveis (CONTROLE: sem irradiação e LASER: irradiação com LASER de Diodo).

A amostra do experimento foi de 80 espécimes divididos aleatoriamente em 8 grupos $(n=10)$. O estudo foi realizado obedecendo a um delineamento em blocos completos casualizados. A variável de resposta quantitativa foi resistência de união à dentina em megapascal (Mpa) por meio de teste de microtração.

Quadro 3: Divisão dos grupos de acordo com os fatores de variação

\begin{tabular}{|ccccc|}
\hline & $\begin{array}{c}\text { Adper } \\
\text { Scotchbond } \\
\text { Multi-Purpose } \\
\text { Plus }\end{array}$ & $\begin{array}{c}\text { Adper }^{\text {TM }} \\
\text { SingleBond 2 }\end{array}$ & $\begin{array}{c}\text { Clearfil } \\
\text { SE Bond }\end{array}$ & $\begin{array}{c}\text { Adper }^{\text {TM }} \\
\text { EasyOne }\end{array}$ \\
\hline CONTROLE & MP & SB & CSE & EO \\
\hline LASER & MP-L & SB-L & CSE-L & EO-L \\
\hline
\end{tabular}


Quadro 4: Composição química dos sistemas adesivos utilizados, de acordo com os fabricantes.

\begin{tabular}{|c|c|}
\hline MATERIAL & COMPOSIÇÃO \\
\hline $\begin{array}{l}\text { Adper }^{\mathrm{TM}} \text { Scotchbond Multi- } \\
\text { Purpose Plus } \\
\text { 3M ESPE, St Paul, EUA }\end{array}$ & $\begin{array}{l}\text { Primer: } \\
\text { HEMA*, Copolímero de ácido polialcenóico, Água } \\
\text { Adesivo: } \\
\text { Bis-GMA }{ }^{* *}, \mathrm{HEMA}^{*} \text {, Canforoquinona }\end{array}$ \\
\hline $\begin{array}{c}\text { Adper }^{\mathrm{TM}} \\
\text { Single Bond } 2 \\
\text { 3M ESPE, St Paul, EUA }\end{array}$ & $\begin{array}{l}\text { BisGMA }{ }^{* *}, \mathrm{HEMA}^{*} \text {, Dimetacrilatos, Etanol, Água, } \\
\text { Fotoiniciador, Copolímero funcional de metacrilato de } \\
\text { ácidos poliacrílico e polialcenóico }\end{array}$ \\
\hline $\begin{array}{l}\text { Clearfil }{ }^{\mathrm{TM}} \text { SE Bond } \\
\text { Kuraray, Osaka, Japão }\end{array}$ & $\begin{array}{l}\text { Primer: } \\
\text { MDP }{ }^{\star \star *} \text {, Hema*, Monômeros Dimetacrilatos, Água, } \\
\text { Fotoiniciador } \\
\text { Adesivo: } \\
\text { MDP }{ }^{\star \star *} \text {, Hema*, Monômeros Dimetacrilatos, Carga } \\
\text { (Micro), Fotoiniciador }\end{array}$ \\
\hline $\begin{array}{c}\text { Adper }^{\mathrm{TM}} \text { EasyOne } \\
\text { 3M ESPE, St Paul, EUA }\end{array}$ & 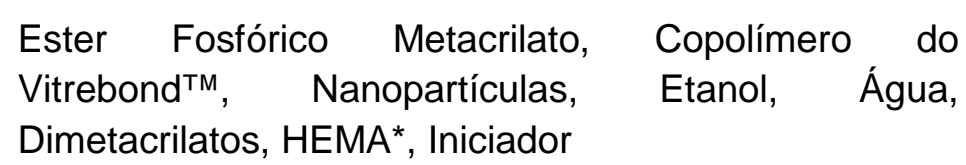 \\
\hline
\end{tabular}

*HEMA: 2-Hidroxi-etilmetacrilato

${ }^{* *}$ Bis-GMA: Bisfenol A Glicidil Metacrilato

${ }^{\star * \star M D P}$ : $10-$ Metacriloiloxidecil dihidrogênio fosfato 
4.2 OBTENÇÃO DOS DENTES HUMANOS

Para este estudo foram utilizados 80 dentes terceiros molares com indicação para exodontia. Os dentes foram obtidos na Clínica de Urgência Odontológica da Faculdade de Odontologia de Bauru - Universidade de São Paulo, mediante assinatura do termo de Doação de Dentes, segundo a resolução no 196 do Conselho Nacional de Saúde (Ministério da Saúde, DF) e após aprovação do Comitê de Ética e Pesquisa em Seres Humanos da Faculdade de Odontologia de Bauru - USP.

Imediatamente após a extração, os dentes foram limpos com curetas (Duflex 55G, SS White Artigos Dentários Ltda., Rio de Janeiro, Brasil) para remoção de restos de tecidos periodontais. Os dentes foram examinados com lupa estereoscópica com aumento de $10 \mathrm{x}$, com a finalidade de detectar possíveis trincas, lesões de cárie ou alterações estruturais que pudessem comprometer o experimento. Posteriormente foram armazenados em solução supersaturada de timol a $0,1 \%$ renovada semanalmente, onde ficaram imersos durante todo o período até o preparo dos espécimes.

\subsection{PLANIFICAÇÃO DAS COROAS PARA A EXPOSIÇÃO DA DENTINA}

Utilizando-se máquina de corte seriada (Isomet ${ }^{\mathrm{TM}}$ Low Speed Saw ${ }^{\circledR}$ Buehler, Lake Bluff, EUA), cada dente selecionado teve sua coroa seccionada, transversalmente no terço oclusal, com disco diamantado (Extec Dia. Wafer blade 5"x.015x1/2, Extec Corp-Einfeld, CT, EUA) em baixa velocidade e sob refrigeração com água, a fim de se remover o esmalte da face oclusal e expor a dentina superficial necessária para os procedimentos adesivos/restauradores. Em sequência, as coroas seccionadas foram submetidas à ação de desgaste na politriz metalográfica (Arotec, Cotia, Brasil), de modo que a face de dentina exposta estivesse em contato com a lixa e paralela a mesma. Primeiramente, para a remoção de eventuais remanescentes de esmalte, foi empregada lixa d'água com granulação 320 (Carbimet Paper Discs, Buehler, Lake Bluff, EUA) em baixa rotação e sob refrigeração com água, substituída periodicamente. Para a planificação final da superfície de dentina, bem como simular a formação de smear layer padronizada, foi utilizada lixa d'água com granulação 600 (Carbimet Paper Discs, Buehler, Lake Bluff, EUA) por 30 segundos. 


\subsection{PREPARO DOS ESPÉCIMES}

Sobre a dentina planificada, uma matriz de silicona de condensação (Zetalabor, Zhermack, São Paulo, Brasil) com dimensões de $6 \mathrm{~mm} \times 6 \mathrm{~mm}$ foi posicionada de forma centralizada, e esmalte de unha foi aplicado ao redor para delimitar a área teste. Após a remoção da silicone de condensação a área teste ficou delimitada pelo esmalte de unha (Figura 6), em seguida cada grupo recebeu tratamento com o respectivo sistema adesivo de acordo com as instruções do fabricante (Quadro 5).

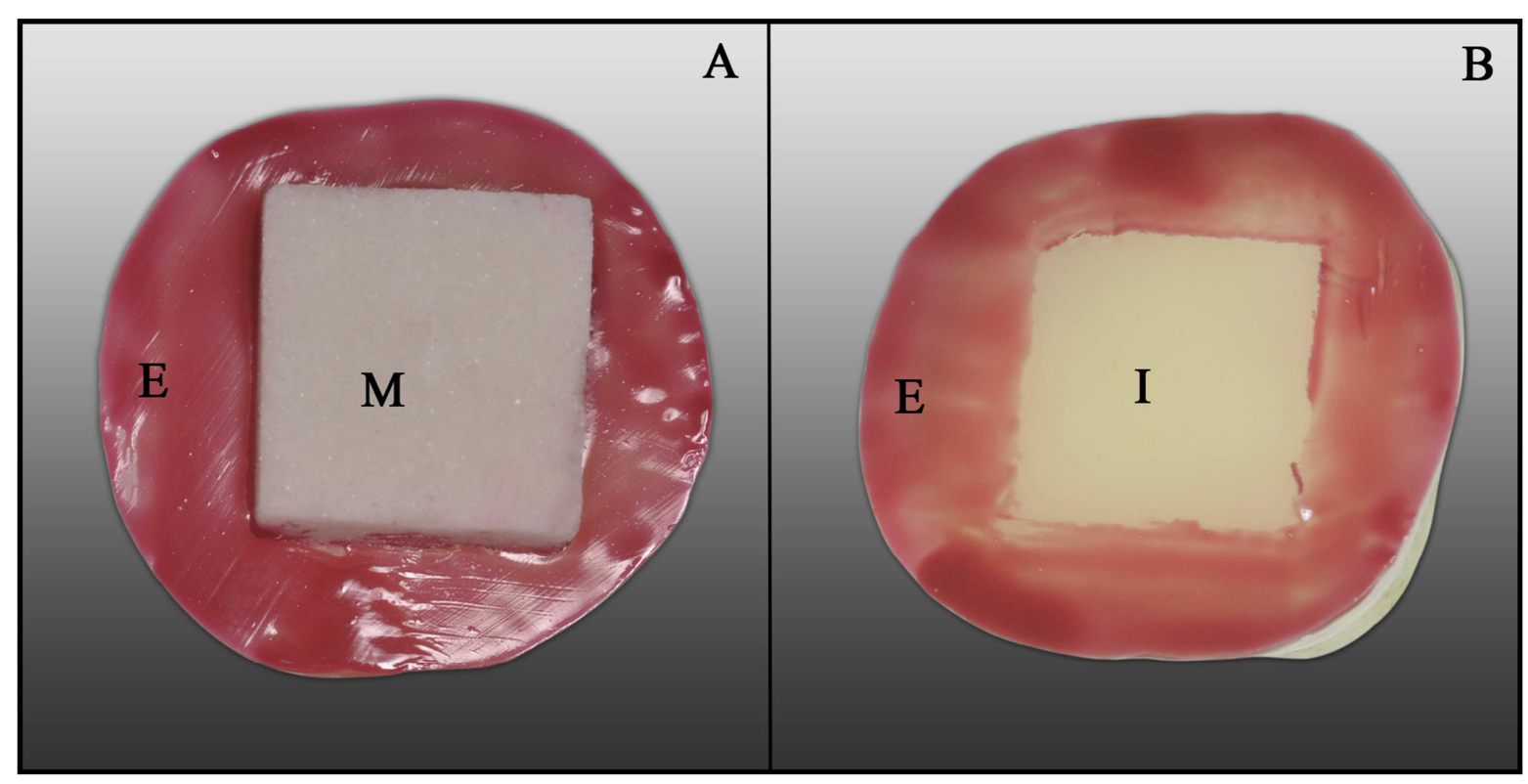

Figura 6: A) Matriz (M) de silicone de condensação de $6 \mathrm{~mm}$ de largura por $6 \mathrm{~mm}$ de comprimento é posicionada de forma centralizada sobre a dentina, e esmalte de unha (E) é utilizado para delimitação da área a ser irradiada. B) Representação da área a ser irradiada (I) determinada através da utilização de esmalte de unha.

Nos grupos LASER (L), após a aplicação do sistema adesivo, mas antes de sua fotoativação, foi irradiado LASER de Diodo (SiroLaser, Sirona Dental Systems, Benshein, Alemanha), no modo contato da fibra ótica, com inclinação de $90^{\circ}$, fazendo-se manualmente uma varredura da área pré-determinada pela matriz, num tempo de 30s. O operador foi calibrado previamente à realização dos testes para padronizar a velocidade de varredura, e durante a irradiação foi utilizado óculos de proteção específico para o LASER utilizado. Os parâmetros utilizados para irradiação do LASER de Diodo estão descritos no quadro 6. 
Quadro 5: Aplicação dos sistemas adesivos segundo as orientações dos fabricantes.

\begin{tabular}{|c|c|}
\hline SISTEMA ADESIVO & TÉCNICA DE APLICAÇÃO \\
\hline $\begin{array}{l}\text { AdperTM Scotchbond } \\
\text { Multi-Purpose Plus } \\
\text { 3M ESPE, St Paul, EUA }\end{array}$ & $\begin{array}{ll}\text { - } & \text { Condicionar a superfície de dentina durante } 15 \text { segundos } \\
\text { com ácido fosfórico a } 37 \% ; \\
\text { - } & \text { Enxaguar com jato de água abundante por } 15 \text { segundos; } \\
\text { - } & \text { Secar, levemente, com jato de ar por } 5 \text { segundos; } \\
\text { - } & \text { Aplicar uma camada do primer; } \\
\text { - } & \text { Secar, gentilmente, durante } 5 \text { segundos; } \\
\text { - } & \text { Aplicar camada do adesivo; } \\
\text { - } & \text { Remover excessos; } \\
\text { - } & \text { Fotoativar por } 20 \text { segundos; } \\
\text { - } & \text { Proceder com a restauração. }\end{array}$ \\
\hline $\begin{array}{l}\text { AdperTM Singlebond } 2 \\
\text { 3M ESPE, St Paul, EUA }\end{array}$ & $\begin{array}{l}\text { - } \quad \text { Condicionar a superfície de dentina durante } 15 \text { segundos } \\
\text { com ácido fosfórico a } 37 \% ; \\
\text { - } \quad \text { Enxaguar com jato de água abundante por } 15 \text { segundos; } \\
\text { - } \quad \text { Secar, levemente, com jato de ar por } 5 \text { segundos; } \\
\text { - } \quad \text { Aplicar camada do adesivo; } \\
\text { - } \quad \text { Remover excessos; } \\
\text { - } \quad \text { Fotoativar por } 20 \text { segundos; } \\
\text { - } \quad \text { Proceder com a restauração. }\end{array}$ \\
\hline $\begin{array}{l}\text { Clearfil TM SE Bond } \\
\text { Kuraray, Osaka, Japão }\end{array}$ & $\begin{array}{ll}\text { - } & \text { Aplicar camada de primer sobre a superfície de dentina } \\
\text { limpa e seca e aguardar } 20 \text { segundos; } \\
\text { - } & \text { Secar com leve jato de ar; } \\
\text { - } & \text { Aplicar uma camada de adesivo; } \\
\text { - } & \text { Remover excessos; } \\
\text { - } & \text { Aplicar leve jato de ar; } \\
\text { - } & \text { Fotoativar por } 20 \text { segundos; } \\
\text { - } & \text { Proceder com a restauração. }\end{array}$ \\
\hline $\begin{array}{c}\text { Adper }^{\text {TM }} \text { EasyOne } \\
\text { 3M ESPE, St Paul, EUA }\end{array}$ & $\begin{array}{ll}\text { - } & \text { Aplicar camada do adesivo sobre a superfície de dentina } \\
\text { limpa e seca e aguardar } 20 \text { segundos; } \\
\text { - } \quad \text { Remover excessos; } \\
\text { - } \quad \text { Secar com leve jato de ar; } \\
\text { - } \quad \text { Fotoativar por } 20 \text { segundos; } \\
\text { - } & \text { Proceder com a restauração. }\end{array}$ \\
\hline
\end{tabular}


Quadro 6: Parâmetros utilizados para irradiação da área teste com LASER de Diodo

\begin{tabular}{|c|c|}
\hline Parâmetro & Valor \\
\hline Energia por pulso & $80 \mathrm{~mJ}$ \\
\hline Frequência & $10 \mathrm{~Hz}$ \\
\hline Potência & $0,8 \mathrm{~W}$ \\
\hline $\begin{array}{l}\text { Área da secção transversal do feixe } \\
\text { (diâmetro da ponta de } 200 \mu \mathrm{m} \text { ) }\end{array}$ & $3,14 \times 10^{-4} \mathrm{~cm}^{2}$ \\
\hline Área irradiada & $36 \mathrm{~mm}^{2}$ \\
\hline Tempo de irradiação & $30 \mathrm{~s}$ \\
\hline Energia Total & $24 \mathrm{~J}$ \\
\hline Densidade de Potência & $2547,77 \mathrm{~W} / \mathrm{cm} 2$ \\
\hline Densidade de Energia & $66,67 \mathrm{~J} / \mathrm{cm}^{2}$ \\
\hline
\end{tabular}

Na sequência o sistema adesivo foi fotoativado com aparelho LED, Blue Star 2 (Microdont, São Paulo, Brasil) com densidade de potência de $1 \mathrm{~W} / \mathrm{cm}^{2}$ por $20 \mathrm{~s}$, com a ponta posicionada a $90^{\circ}$ da superfície do espécime, cujo diâmetro permitia a cobertura de toda a área teste. Em seguida foi inserida pela técnica incremental a resina composta Filtek ${ }^{\text {TM }}$ Z250 (3M ESPE, St Paul, EUA) com deposição consecutiva de três incrementos de $1,5 \mathrm{~mm}$ de espessura. A fotoativação de cada incremento foi realizada com o mesmo aparelho LED por 20s. Após o aplicação da resina, os dentes foram imersos em água deionizada e mantidos em estufa a temperatura de $3^{\circ} \mathrm{C}$ por período de 7 dias. 


\subsection{OBTENÇÃO DOS PALITOS}

Após o período de armazenagem os espécimes foram removidos da estufa e secos, para que cada um fosse fixado, com cera pegajosa, em dispositivo metálico de base plana, adaptável na máquina de cortes seriados (Isomet ${ }^{\mathrm{TM}}$ Low Speed Saw $^{\circledR}$, Buehler, Lake Bluff, EUA) para seccionamento com disco diamantado (Extec Dia. Wafer blade 5"x.015x1/2, Extec Corp-Einfeld, EUA), em baixa velocidade e sob refrigeração com água. Primeiramente, o seccionamento por desgaste foi realizado no sentido mésio-distal da coroa, gerando fatias de espessura média de $1 \mathrm{~mm}$, as quais permaneceram presas na base do dispositivo pela ação retentiva da cera. Em seqüência, girando-se a base metálica em $90^{\circ}$, fati as semelhantes foram obtidas no sentido vestíbulo-lingual do mesmo dente, obtendo-se assim, espécimes em forma de palito com área transversal de aproximadamente $1 \mathrm{~mm}^{2}$ (Figura 7). Os espécimes foram testados imediatamente após o corte.

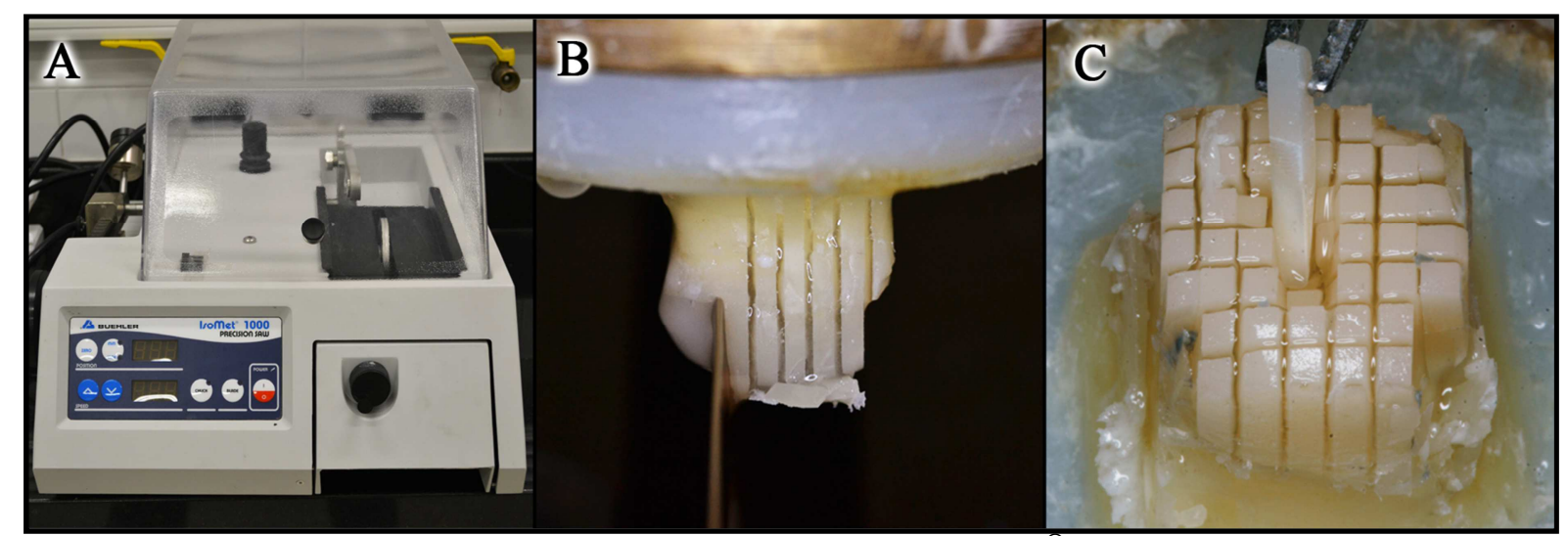

Figura 7: A) Máquina de cortes seriados (Isomet ${ }^{\mathrm{TM}}$ Low Speed Saw ${ }^{\circledR}$, Buehler, Lake Bluff, EUA). B) O primeiro corte é realizado no sentido mésio-distal da coroa, gerando fatias de aproximadamente $1 \mathrm{~mm}$ de espessura. C) Corte semelhante é realizado, agora no sentido vestíbulo-lingual do mesmo dente, gerando palitos com área transversal de aproximadamente $1 \mathrm{~mm}^{2}$. 
4.6 TESTE DE MICROTRAÇÃO

Previamente ao teste, foi medida a área transversal da interface adesiva com paquímetro digital (Digmatic Caliper, Mitutoyo Sul Americana, Rio de Janeiro, Brasil), cujos valores foram inseridos no software BlueHill Lite (BlueHill ${ }^{\circledR}$ Materials Testing Software, Norwood, EUA). Em seguida os palitos foram fixados, individualmente, ao dispositivo de microtração similar ao de Bencor multi T (Danville Engeneering, Danville, CA, EUA) adaptado à máquina de ensaios universal INSTRON 3342 (Illinois Tool Works, Norwood, EUA). Para tanto, foi empregado um adesivo à base de cianocrilato (Loctite Super Bonder Gel Control, Henkel Ltda, São Paulo, Brasil) em ambas as extremidades de cada corpo de prova, de modo a posicionar a interface adesiva perpendicular à força de tração desempenhada pela máquina (Figura 8). O teste foi realizado com velocidade de $0,5 \mathrm{~mm} / \mathrm{min}$ (ISO TR 11405), utilizando-se uma célula de carga de $500 \mathrm{~N}$ para captação das forças. A resistência de união foi calculada automaticamente pelo software a partir da razão entre força máxima (Kgf) e área transversal da interface adesiva $\left(\mathrm{cm}^{2}\right)$ previamente fornecida, obtendo-se valores em megapascal (MPa).

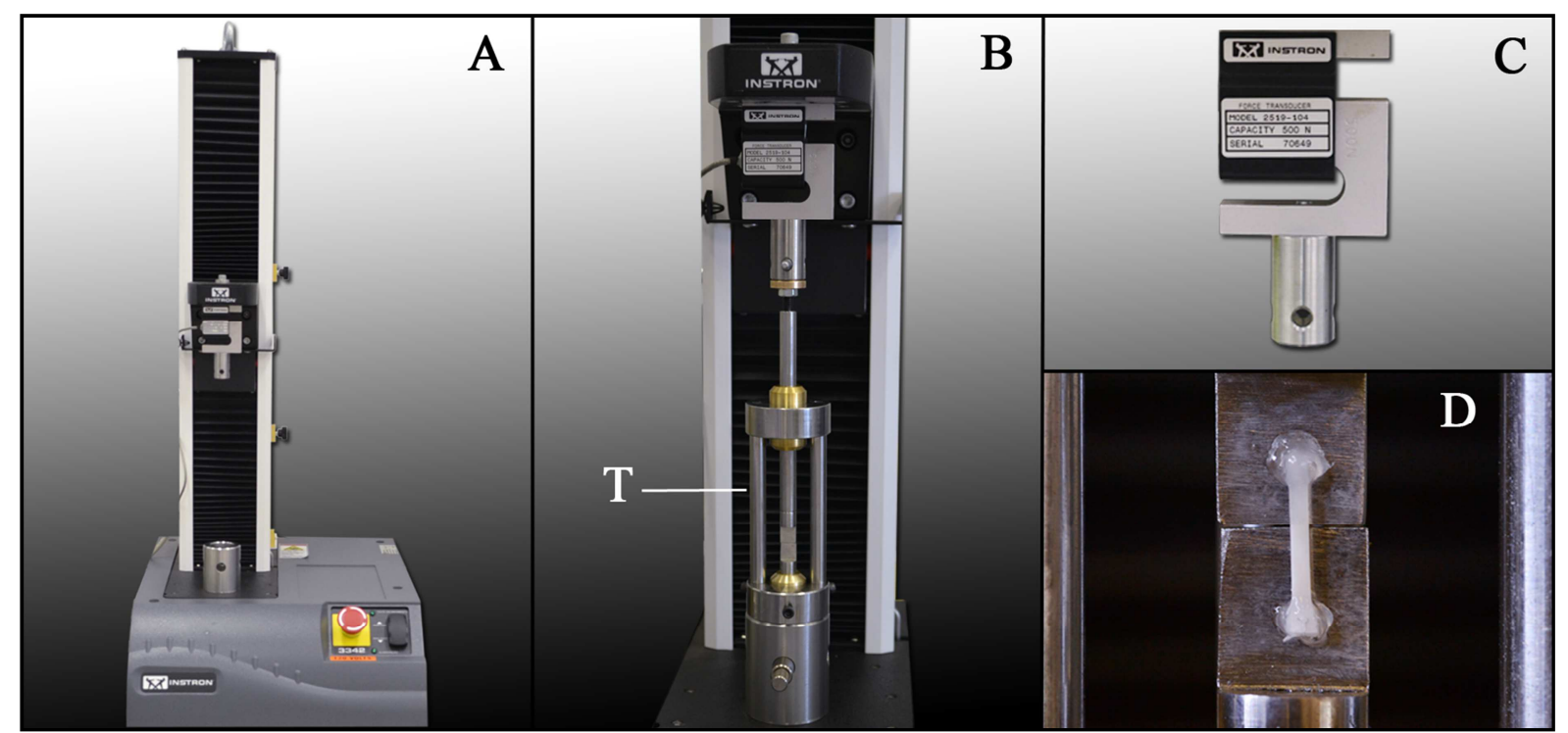

Figura 8: O teste de microtração foi conduzido na máquina de ensaios universal INSTRON $3342(A)$ (Illinois Tool Works, Norwood, EUA) utilizando-se dispositivo de microtração similar ao de Bencor multi $\mathrm{T}$ (T) (Danville Engeneering, Danville, CA, EUA) com célula de carga de $500 \mathrm{~N}$ (C). Os palitos foram fixados, com adesivo à base de cianocrilato (Loctite Super Bonder Gel Control, Henkel Ltda, São Paulo, Brasil) posicionando a interface adesiva perpendicular à força de tração (D). 


\subsection{ANÁLISE DE FRATURA}

As superfícies fraturadas de ambos os segmentos foram analisadas quanto ao tipo de fratura com o auxílio de estereomicroscópio (Dino Lite Microscope 100x, AnMo Electronics Corp, New Taipei City, Taiwan), e foram classificadas em: adesiva (A) quando ocorrerem na interface adesiva; coesiva em dentina (CD) quando ocorrerem em substrato dentário (dentina); coesiva em resina composta (CR) quando a fratura ocorrer no material restaurador (resina composta) e mista (M) quando a fratura for adesiva e coesiva. A quantidade de cada tipo de fratura foi convertida em porcentagem para avaliação. Ainda utilizando este aparelho foi realizada uma avaliação quanto a presença de remanescente de esmalte de unha, bem como de adesivo cianoacrilato que eventualmente possa ter escorrido até a interface (Figura 9). Os espécimes que apresentavam estas características tiveram seus valores de resistência de união excluídos.

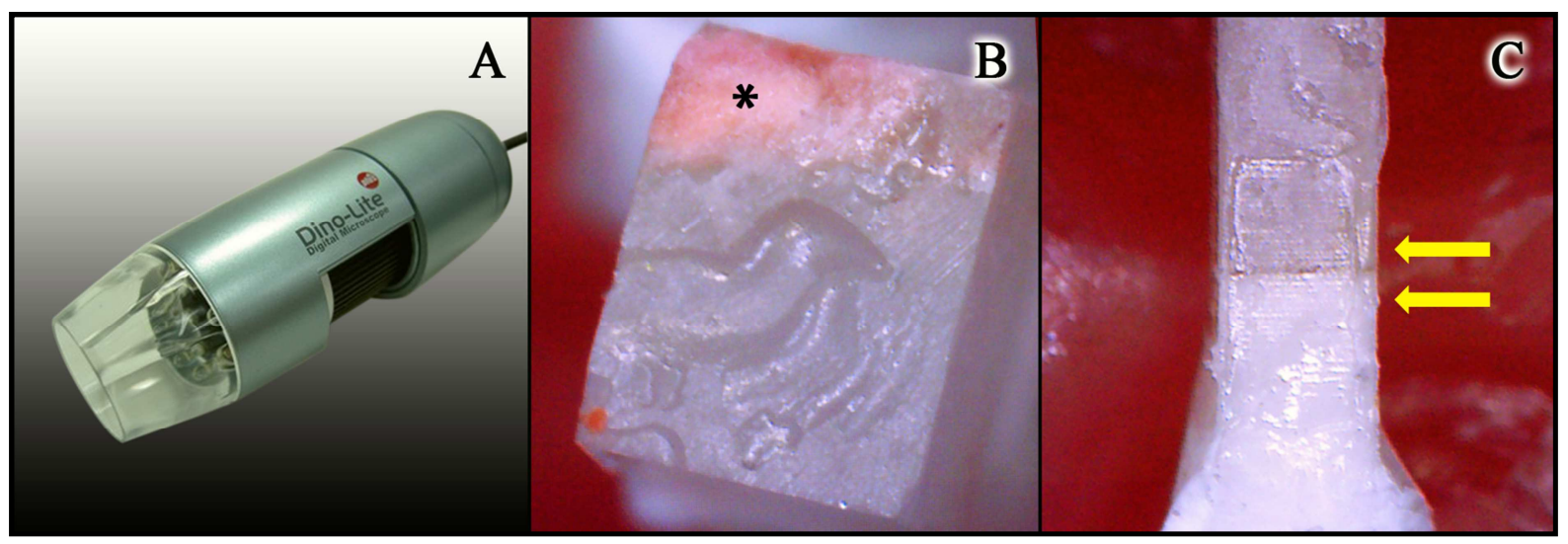

Figura 9: A) Estereomicroscópio (Dino Lite Microscope 100x, AnMo Electronics Corp, New Taipei City, Taiwan) utilizado para análise de qualidade e de fratura. B) Presença de remanescente de esmalte de unha* determinou a exclusão deste espécime. C) Presença de adesivo cianoacrilato na interface adesiva compromete a avaliação da resistência de união e determina também a exclusão do espécime. 


\subsection{ANÁLISE ESTATÍSTICA}

Os valores de resistência de união foram submetidos ao teste de Shapiro-Wilks para averiguar se a amostra apresentava uma distribuição normal. Aprovado pelo teste de normalidade, os valores de resistência de união foram analisados por análise de variância (ANOVA) a dois critérios seguido de Tukey para comparações individuais e múltiplos testes "t" para comparações entre grupos teste e controle de cada sistema adesivo. 
5 Resultados 

5 RESULTADOS

Avaliando-se os resultados obtidos, observa-se que o fator "Sistemas Adesivos" foi significante para ANOVA a dois critérios $(n=20)$, com o sistema adesivo EO apresentando diferença de resistência de união aos demais sistemas adesivos (Tabela 1). O fator "LASER" não apresentou diferença quando todos os espécimes testados foram distribuídos em apenas dois grupos (CONTROLE x LASER) ( $n=40)$, no entanto, foi observada uma interação entre os fatores (Tabela 2 e Apêndice $C$ ).

A partir dos resultados analisados com múltiplos testes "t" (Tabela 3 e Gráfico 1), comparando individualmente os grupos CONTROLE e LASER de cada um dos sistemas adesivos, foi observado um aumento significativo na resistência de união dos adesivos Adper' ${ }^{\mathrm{TM}}$ SingleBond 2 (SB) e Adper ${ }^{\mathrm{TM}}$ EasyOne (EO) quando a irradiação com LASER de Diodo foi realizada. Os valores de resistência de união dos sistemas adesivos MP e CSE mantiveram-se sem diferenças com e sem a irradiação com LASER de Diodo.

Observou-se ainda, através do teste Tukey para comparações individuais (Apêndice C), que o adesivo EO apresenta resultados inferiores ao demais adesivos, no entanto, após a irradiação com LASER de Diodo, seus valores de resistência de união aproximam-se, mantendo diferença estatisticamente significante apenas para o adesivo SB, que após a irradiação com LASER passou a ter o maior valor de resistência de união. 
Tabela 1 - Média \pm desvio padrão dos valores de resistência de união (MPa) agrupados no fator "Sistema Adesivo" $(\mathrm{n}=20)$

\begin{tabular}{|c|c|c|c|}
\hline MP & SB & CSE & EO \\
\hline $37,96 \pm 9,27 \mathrm{~A}$ & $38,59 \pm 8,98 \mathrm{~A}$ & $40,83 \pm 12,39 \mathrm{~A}$ & $24,77 \pm 8,17 \mathrm{~B}$ \\
\hline
\end{tabular}

Letras maiúsculas representam diferença $(p<0,05)$ observada através de ANOVA a dois critérios seguido de Tukey.

Tabela 2 - Média \pm desvio padrão dos valores de resistência de união (MPa) agrupados no fator "LASER" $(\mathrm{n}=40)$

\begin{tabular}{cc}
\hline CONTROLE & LASER \\
\hline $34,24 \pm 13,77$ & $36,83 \pm 8,78$ \\
\hline
\end{tabular}

Tabela 3 - Média \pm desvio padrão da resistência de união (MPa) obtida por cada grupo individualmente $(n=10)$

\begin{tabular}{ccc}
\hline Sistema Adesivo & Controle & LASER de Diodo \\
\hline MP & $40,10 \pm 10,95 \mathrm{Aab}$ & $35,82 \pm 7,17 \mathrm{Aab}$ \\
SB & $33,49 \pm 6,77 \mathrm{Aab}$ & $43,69 \pm 8,15 \mathrm{Ba}$ \\
CSE & $43,71 \pm 15,71 \mathrm{Aa}$ & $37,95 \pm 7,66 \mathrm{Aab}$ \\
EO & $19,67 \pm 5,86 \mathrm{Ac}$ & $29,87 \pm 6,98 \mathrm{Bbc}$
\end{tabular}

Letras maiúsculas representam diferenças ( $\mathrm{p}<0,05)$ entre linhas (teste " $\mathrm{t}$ "). Letras minúsculas representam diferenças $(p<0,05)$ individuais (teste Tukey).

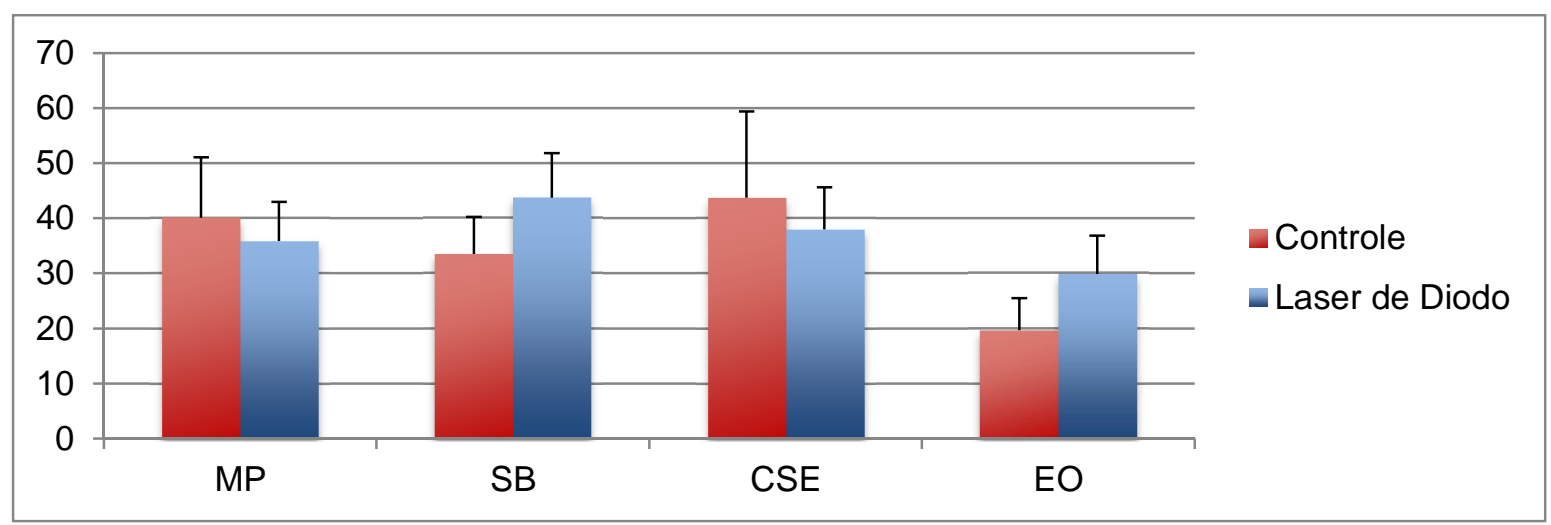

Gráfico 1: Representação gráfica das médias e desvio padrão da resistência de união obtida após testes de microtração (MPa). 
O tipo de fratura (Figura 10) predominante em todos os grupos testados foi a fratura do tipo adesiva, no entanto, observa-se um aumento na quantidade de fraturas coesivas em resina no grupo SB-L. A porcentagem de cada tipo de fratura está descrita na Tabela 4, e representada graficamente no Gráfico 2.

Tabela 4 - Porcentagem do tipo de fratura de cada grupo

\begin{tabular}{ccccc}
\hline & A & CR & CD & M \\
\hline MP & $83 \%$ & $0 \%$ & $3 \%$ & $14 \%$ \\
SB & $94 \%$ & $3 \%$ & $3 \%$ & $0 \%$ \\
CSE & $79 \%$ & $8 \%$ & $0 \%$ & $13 \%$ \\
EO & $76 \%$ & $3 \%$ & $0 \%$ & $21 \%$ \\
MP-L & $85 \%$ & $10 \%$ & $0 \%$ & $5 \%$ \\
SB-L & $65 \%$ & $25 \%$ & $5 \%$ & $5 \%$ \\
CSE-L & $96 \%$ & $0 \%$ & $4 \%$ & $0 \%$ \\
EO-L & $96 \%$ & $0 \%$ & $0 \%$ & $4 \%$ \\
\hline
\end{tabular}

(A) Adesiva, (CR) Coesiva em Resina, (CD) Coesiva em Dentina, (M) Mista

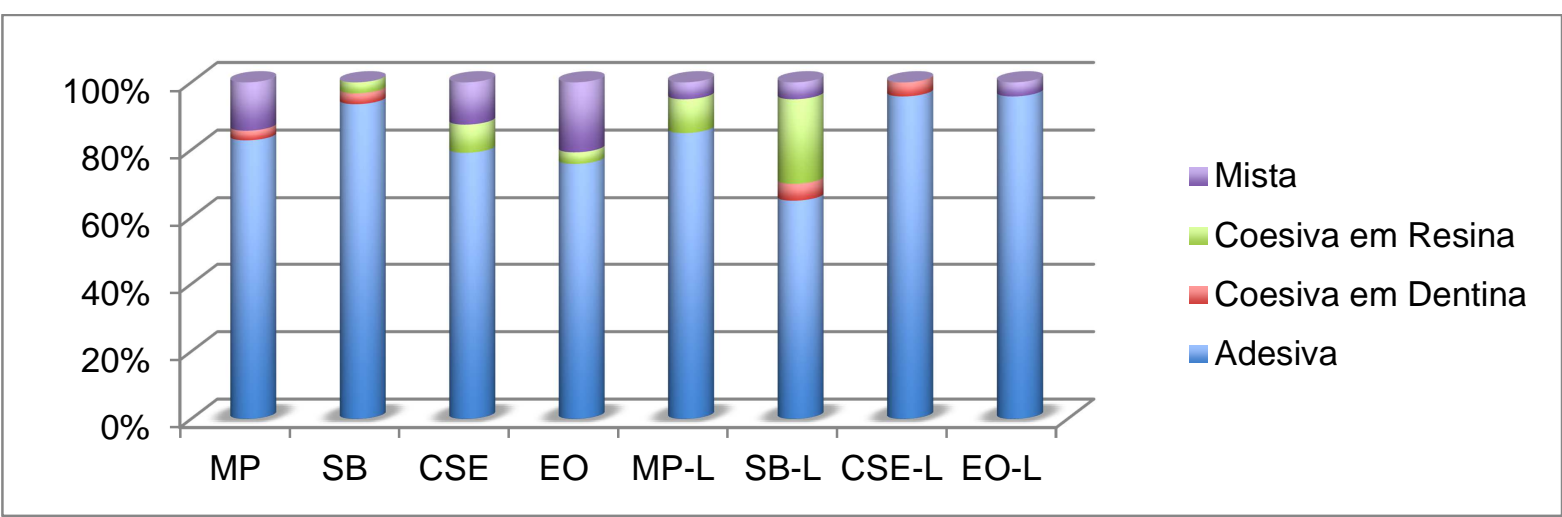

Gráfico 2 - Representação gráfica da porcentagem do tipo de fratura ocorrido em cada grupo após o teste de microtração.

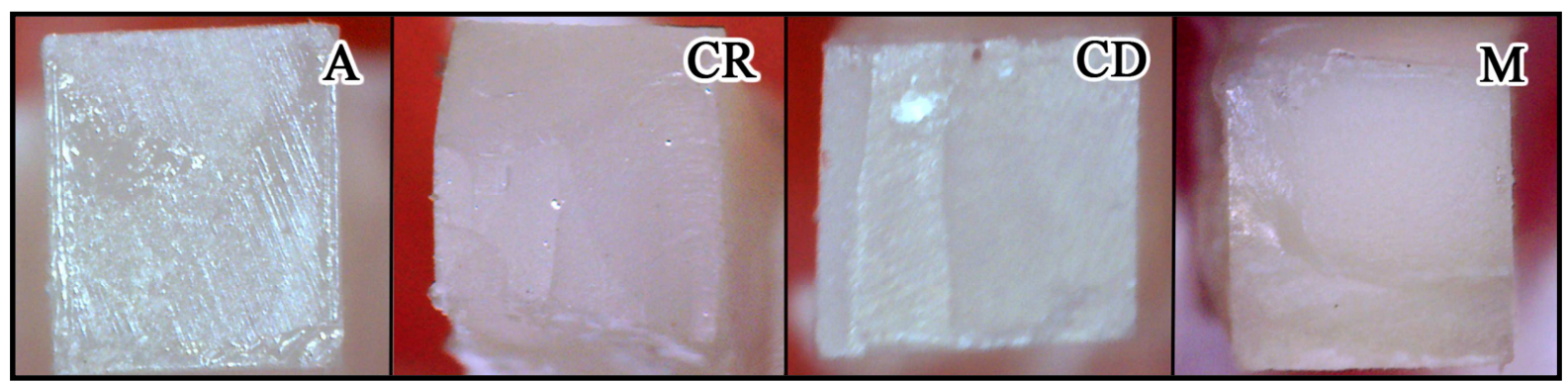

Figura 10: Imagens representativas de fraturas adesiva (A), coesiva em resina (CR), coesiva em dentina $(C D)$ e mista $(M)$, obtidas com estereomicroscópio com aumento de 100x. 

6 Discussão 



\section{DISCUSSÃO}

A união dos sistemas adesivos à dentina continua sendo um dos principais desafios relacionados às restaurações de resina composta (MJOR; DAHL, MOORHEAD, 2002; SONCINI et al., 2007; SPENCER et al., 2010), e neste sentido, intensa investigação é realizada em busca de estratégias para a promoção de uma adesão mais eficiente à este substrato (SCHERRER, CESAR e SWAIN, 2010; DE MUNCK et al., 2012). O presente estudo investigou os efeitos da irradiação com LASER de Diodo sobre diferentes grupos de sistemas adesivos utilizados atualmente, através da variável de resposta "resistência de união", dada em MPa, e obtida através do teste de microtração.

Os resultados obtidos desta avaliação in vitro determinam a rejeição da primeira hipótese nula proposta, ou seja, diferenças nos valores de resistência de união foram encontrados entre os sistemas adesivos, independente da irradiação com LASER de Diodo. Em revisões meta-analíticas realizadas por Scherrer, Cesar e Swain (2010) e De Munck et al. (2012), em que se agregam valores de resistência de união de diversos de trabalhos já publicados na literatura, foi observada também uma variação nos resultados de resistência de união entre os sistemas adesivos testados. Os autores observaram uma média de valores de resistência de união (dos diversos trabalhos avaliados) muito próxima aos valores obtidos nos grupos controle dos sistemas adesivos MP, SB e CSE no presente estudo, comprovando os resultados obtidos na presente investigação. O sistema adesivo EO não foi incorporado nas revisões devido a menor quantidade de trabalhos realizados utilizando este material, no entanto, os autores observaram que sistemas adesivos de passo único apresentam valores de resistência de união inferiores aos demais, como observado no presente estudo.

Quando os sistemas adesivos foram irradiados com LASER de Diodo, variações entre a resistência de união entre os sistemas adesivos se mantiveram, no entanto, foram reduzidas, principalmente devido ao aumento substancial obtido pelo grupo EO-L. O grupo SB-L também apresentou um aumento significativo da resistência de união com o tratamento com LASER de Diodo, determinando também a rejeição da segunda hipótese nula. A irradiação com LASER de Diodo influenciou na resistência de união de dois, dos quatro sistemas adesivos avaliados, permitindo que os sistemas adesivos que apresentavam resistência de união inferior no grupo 
controle passassem a não apresentar esta diferença após a irradiação com LASER de Diodo.

Recentemente, Marimoto et al. (2012) observaram resultados favoráveis nos mesmos grupos de sistemas adesivos que apresentaram aumento da resistência de união no presente trabalho (convencional de dois passos e autocondicionante de passo único). Em seu estudo foi utilizado LASER Nd:YAG com densidade de energia de $1200 \mathrm{~J} / \mathrm{cm}^{2}$, irradiado após a aplicação dos sistemas adesivos sobre a dentina, antes de sua fotoativação. Observou-se um aumento significativo da resistência de união em teste de cisalhamento. Segundo os autores, a irradiação com LASER sobre a dentina infiltrada pelo sistema adesivo é capaz de provocar uma fusão, criando um novo substrato mais susceptível a adesão.

Por outro lado, alguns autores não encontraram diferenças significantes na resistência de união à dentina de sistemas adesivos irradiados com LASER após a sua aplicação, mas previamente à sua fotoativação. Matos et al. (1999) investigaram a influência da irradiação do LASER Nd:YAG com densidade de energia de $254,78 \mathrm{~J} / \mathrm{cm}^{2}$ sobre o adesivo SB, no entanto, os resultados de resistência de união não diferiram dos resultados obtidos nos grupos controle. Malta et al. (2008) também não notaram alteração na resistência de união ao irradiar o adesivo SB com LASER $\mathrm{Nd}$ :YAG, utilizando densidade de energia de $100 \mathrm{~J} / \mathrm{cm}^{2}$, após a sua aplicação sobre a dentina, mas antes de sua fotoativação. Franke et al. (2006) avaliaram o efeito da densidade de energia na eficiência da irradiação com LASER Nd:YAG também sobre o sistema adesivo SB. O autor obteve resultados favoráveis apenas quando a densidade de energia utilizada foi de $5 \mathrm{~J} / \mathrm{cm}^{2}$. Densidades superiores $\left(10\right.$ e $50 \mathrm{~J} / \mathrm{cm}^{2}$ ) apresentaram resistência de união semelhante ao grupo controle.

Comparando os resultados obtidos pelos autores citados, é possível notar controvérsias na determinação de uma densidade de energia ideal. Enquanto Matos et al. (1999), Malta et al. (2008) e Franke et al. (2006) observaram que altas densidades energia (superiores a $10 \mathrm{~J} / \mathrm{cm}^{2}$ ) não alteram a resistência de união dos sistemas adesivos, o presente trabalho (densidade de energia de $66,67 \mathrm{~J} / \mathrm{cm}^{2}$ ), e principalmente o trabalho de Marimoto et al. (2012), (1200 $\left./ \mathrm{cm}^{2}\right)$, sugerem que valores maiores de densidade de energia são capazes de favorecer o processo de adesão. Provavelmente esta divergência de resultados está atrelada à influência dos demais parâmetros do LASER, como densidade de potência, potência, entre outros. 
A tabela 5 relaciona resultados obtidos pelos autores citados utilizando a mesma técnica de irradiação e o mesmo sistema adesivo (SB), porém com parâmetros distintos para irradiação com LASER.

Tabela 5: Relação entre os parâmetros utilizados com resultados obtidos em estudos que utilizaram o mesmo sistema adesivo (SB).

\begin{tabular}{ccccc}
\hline Autores & $\begin{array}{c}\text { Densidade de } \\
\text { Energia }\left(\mathbf{J} / \mathbf{c m}^{2}\right)\end{array}$ & $\begin{array}{c}\text { Densidade de } \\
\text { Potência }\left(\mathbf{W} / \mathbf{c m}^{2}\right)\end{array}$ & $\begin{array}{c}\text { Potência } \\
(\mathbf{W} \text { ou J/s) }\end{array}$ & Resultado \\
\hline Matos et al., 1999 & $254,78^{*}$ & $477,70^{*}$ & 0,6 & Sem efeito \\
Franke et al., 2006 & $5^{*}$ & $14,15^{*}$ & $1 \mathrm{~W}$ & Favorável \\
Franke et al., 2006 & $10^{\star}$ & $14,15^{*}$ & $1 \mathrm{~W}$ & Sem efeito \\
Franke et al., 2006 & $50^{\star}$ & $14,15^{*}$ & $1 \mathrm{~W}$ & Sem efeito \\
Malta et al., 2008 & $100^{*}$ & $\dagger$ & $1 \mathrm{~W}$ & Sem efeito \\
Marimoto et al., 2012 & $1200^{*}$ & $1741,64^{*}$ & $1,4 \mathrm{~W}$ & Favorável \\
Presente trabalho & 66,67 & 2547,78 & $0,8 \mathrm{~W}$ & Favorável \\
\hline
\end{tabular}

* Valor fornecido pelo autor.

${ }^{*}$ Valor calculado através de outros dados fornecidos pelo autor.

† Ausência de informações suficientes para o cálculo.

Analisando-se a tabela, verifica-se que valores mais altos de densidade de potência foram utilizados no presente trabalho e no estudo de Marimoto et al. (2012), comparados com a densidade de potência utilizada por Matos et al. (1999) e Franke et al. (2006). Diferenças na densidade de potência podem ser causadas pela variação da potência utilizada (quantidade de energia emitida por segundo), bem como pela variação do diâmetro do feixe de luz que atinge o tecido. Matos et al. (1999) utilizou uma potência reduzida, associada a uma fibra ótica de diâmetro de $400 \mu \mathrm{m}$, o que proporcionou uma baixa densidade de potência. No estudo de Franke et al. (2006) foi utilizada uma lente, que aumentava o diâmetro do feixe de luz para $3 \mathrm{~mm}$, reduzindo drasticamente a densidade de potência. No presente trabalho e no estudo de Marimoto et al. (2012) o LASER foi irradiado com potência de 0,8W e $1,4 \mathrm{~W}$, diretamente sobre a dentina (modo contato e $0,5 \mathrm{~cm}$ de distância), com fibras óticas de diâmetro de 200 e $320 \mu \mathrm{m}$ respectivamente, determinando uma maior densidade de potência.

Estas condições permitem maior penetração, e maior energia descarregada por área em cada pulso, o que, de fato, favorece o processo de fusão e 
recristalização da hidroxiapatita dentinária, como constatado através de microscopia eletrônica de varredura por Marimoto et al. (2012). A irradiação com menores densidades de potência não apresentam esta capacidade, porém, quando associadas a baixas densidades de energia, podem favorecer a penetração do sistema adesivo, como observado também em microscopia eletrônica de varredura por Franke et al. (2006). Portanto é possível que existam dois métodos distintos de obtenção de uma resistência de união mais eficiente à dentina: um utilizando altas densidades de energia e potência provocando a fusão e recristalização da hidroxiapatita em meio ao sistema adesivo, e outro utilizando baixas densidades de energia e de potência, visando uma penetração mais eficiente do sistema adesivo. Densidades de energia e de potência medianas aparentemente não provocam nenhum destes dois efeitos, justificando a ausência de aumento na resistência de união encontrada no trabalho de Matos et al., (2000) e quando maiores densidades de energia foram utilizadas no estudo de Franke et al., (2006). Avaliações não puderam ser realizadas em relação ao estudo de Malta et al. (2008) devido a ausência de informações como a espessura da fibra ótica, ou do feixe de luz, bem como a área total irradiada, fundamentais para o cálculo da densidade de potência e da densidade de energia.

É possível que o presente estudo tenha apresentado um aumento na resistência de união decorrente da fusão e recristalização da hidroxiapatita, em meio ao sistema adesivo, como observado por Marimoto et al. (2012) em MEV, pois além de também ter sido utilizado uma alta densidade de potência, o aumento da quantidade de fraturas coesivas em resina do grupo SB-L pode sugerir esta interpretação, uma vez que indica uma maior resistência tanto da interface adesiva como do substrato dentinário. Avaliações morfológicas e químicas da camada híbrida irradiada com LASER de Diodo são necessárias para evidenciar estas hipóteses.

Quanto aos sistemas adesivos que não obtiveram aumento da resistência de união após irradiação com LASER de Diodo (MP e CSE), informações são mais escassas na literatura. Matos et al. (2000) avaliaram a resistência de união através de teste de tração, do sistema adesivo CSE após irradiá-lo com LASER Nd:YAG. Os resultados obtidos corroboram com o presente estudo, ou seja, os valores de resistência de união não aumentaram após a irradiação do LASER sobre o sistema adesivo CSE quando a avaliação foi realizada sobre a dentina, no entanto, também 
não houve queda nestes valores. Apesar do presente estudo abordar apenas a adesão em dentina, é conveniente salientar que neste estudo de Matos et al. (2000) a irradiação do LASER Nd:YAG promoveu aumento da resistência de união do sistema adesivo CSE ao esmalte, confirmando que o melhor momento para irradiação com LASER é após a aplicação do sistema adesivo, mas previamente à sua fotoativação.

Em relação ao sistema adesivo AdperTM Scotchbond Multi-Purpose Plus (MP), Gonçalves, Araújo e Damião (1999) constataram aumento na resistência de união em teste de cisalhamento, com a utilização do LASER Nd:YFL. Apesar deste LASER emitir luz no mesmo comprimento de onda do LASER Nd:YAG, devido a alta energia por pulso e ampla espessura do feixe de luz, o autor utilizou frequência e densidade de energia altamente reduzidas $\left(0,3 \mathrm{~Hz}\right.$ e $\left.1,31 \mathrm{~J} / \mathrm{cm}^{2}\right)$. Devido às grandes proporções deste LASER experimental, sua utilização na clínica é inviável, e as mesmas condições experimentais não são reproduzíveis com os aparelhos de LASER convencionais utilizados atualmente, entretanto, este estudo sugere que condições proporcionais de irradiação com LASER sobre o sistema adesivo MP sejam capazes de favorecer a resistência de união à dentina.

O presente estudo não evidenciou alterações significativas na resistência de união dos sistemas adesivos MP e CSE após sua irradiação com LASER de Diodo, no entanto, a possibilidade de viés causado pelas limitações do teste de microtração não pode ser descartada. Uma quantidade não calculada de palitos do grupo MP-L não se fraturaram durante o teste de microtração, e provocavam falha do adesivo cianoacrilato (Loctite Super Bonder Gel Control, Henkel Ltda, São Paulo, Brasil) empregado para sua fixação na máquina de ensaios universal. Estes palitos foram descartados devido a ausência de valor de fratura, apesar de muitas vezes provocarem a falha do adesivo cianoacrilato com valores de resistência de união superiores a $50 \mathrm{MPa}$. Dessa forma, não deve ser descartada por completo a possibilidade do LASER de Diodo também influenciar a resistência de união do sistema adesivo MP. Novos estudos utilizando metodologias distintas são necessários para investigar a influência da irradiação do LASER de Diodo sobre os diferentes sistemas adesivos.

Outra hipótese para os diferentes comportamentos dos sistemas adesivos após a irradiação com LASER de Diodo remete à suas composições. A luz LASER, como toda luz, possui melhor interação com determinadas substâncias e tecidos, 
dependendo de seu comprimento de onda. A luz emitida, por exemplo, pelo LASER Er:YAG (2940nm) é altamente absorvida pela água, e também pela hidroxiapatita, e por isso determina um rápido e superficial aquecimento, causando o efeito da ablação no dente, sem, no entanto, transmitir grande quantidade de calor para a polpa dentária (KELLER et al., 1998). Diferenças na composição de cada sistema adesivo podem contribuir para uma maior ou menor absorção da luz emitida pelo LASER testado, causando diferentes consequências sobre a adesão em dentina.

Um estudo realizado no departamento de Dentística, Endodontia e Materiais Odontológicos da FOB-USP, cujos dados ainda não foram publicados, avaliou a influência no aquecimento intracâmara pulpar causado pela irradiação de dentes bovinos com LASER de Diodo e LASER Nd:YAG, sobre diferentes sistemas adesivos previamente às suas fotoativações. Os sistemas adesivos empregados, bem como os parâmetros utilizados, foram similares aos do presente estudo, com a espessura de dentina estabelecida em $1 \mathrm{~mm}$. Os resultados obtidos demonstraram que a geração de calor causada pela irradiação com LASER foi semelhante para todos os sistemas adesivos testados, o que não corrobora com a hipótese de que os sistema adesivos apresentam absorção distinta da luz LASER. Além deste resultado, os autores observaram que o LASER Nd:YAG gerou temperaturas significantemente maiores que a irradiação com LASER de Diodo, superando inclusive o limite de segurança de 5,5ㄷ estabelecido por Zach e Cohen (1965). O LASER de Diodo apresentou médias de variação de temperatura inferiores aos $5,5^{\circ} \mathrm{C}$, o que aparentemente determina maior segurança em sua utilização com relação ao aumento da temperatura intracâmara pulpar, no entanto estudos variando os parâmetros utilizados são necessários para esta constatação

Em vista do conhecimento adquirido no presente estudo, é possível afirmar que o LASER de Diodo apresenta-se como uma alternativa promissora para a associação com os sistemas adesivos. Sua irradiação influenciou positivamente a resistência de união de sistemas adesivos que também apresentaram resultados favoráveis frente a utilização do LASER Nd:YAG. Certamente existe a necessidade de novas avaliações, alterando-se os parâmetros utilizados, tipos de teste, e principalmente avaliações morfológicas e químicas para maior entendimento do fenômeno que ocorre na interface irradiada, assim como estudos longitudinais para avaliação da durabilidade desta camada hibrida irradiada. 
7 Conclusões 

7 CONCLUSÕES

Baseado nos resultados obtidos, pode-se concluir que a irradiação com LASER de Diodo sobre sistemas adesivos já aplicados na dentina, porém previamente à fotoativação, consiste numa técnica promissora capaz de aumentar valores de resistência de união à dentina, na dependência do tipo de sistema adesivo empregado e dos parâmetros LASER utilizados. 

$\underline{\text { Referências }}$ 



\section{REFERÊNCIAS}

Amaral FLB, Colucci V, Souza-Gabriel AE, Chinelatti MA, Palma-Dibb RG, Corona SAM. Adhesion to Er:YAG laser-prepared dentin after long-term water storage and thermocycling. Oper Dent. 2008;33(1):51-8.

Ansari ZJ, Fekrazad R, Feizi S, Younessian F, Kalhori KAM, Gutknecht N. The effect of an $\mathrm{Er}, \mathrm{Cr}: Y S G G$ laser on the micro-shear bond strength of composite to the enamel and dentin of human permanent teeth. Lasers Med Sci. 2012;27(4):761-5.

Bahar A, Tagomori S. The effect of normal pulsed Nd-YAG laser irradiation on pits and fissures in human teeth. Caries Res. 1994;28(6):460-7.

Bowen RL. Adhesive bonding of various materials to hard tooth tissues. 3. Bonding to dentin improved by pre-treatment and the use of surface-active comonomer. $J$ Dent Res. 1965;44(5):903-5.

Bowen RL. Adhesive bonding of various materials to hard tooth tissues. I. Method of determining bond strength. J Dent Res. 1965;44:690-5.

Bowen RL. Adhesive bonding of various materials to hard tooth tissues. II. Bonding to dentin promoted by a surface-active comonomer. J Dent Res. 1965;44(5):895-902.

Brannstrom M, Johnson G. Effects of various conditioners and cleaning agents on prepared dentin surfaces: a scanning electron microscopic investigation. J Prosthet Dent. 1974;31(4):422-30.

Breschi L, Mazzoni A, Ruggeri A, Cadenaro M, Di Lenarda R, De Stefano Dorigo E. Dental adhesion review: aging and stability of the bonded interface. Dent Mater. 2008;24(1):90-101

Brudevold F, Buonocore M, Wileman W. A report on a resin composition capable of bonding to human dentin surfaces. J Dent Res. 1956;35(6):846-51.

Brulat N, Leforestier E, Rocca JP, Darquet-Cerretti E, Bertrand MF. Shear bond strength of self-etching adhesive systems to Er:YAG laser-prepared dentine with and without pulpal pressure simulation. Photomed Laser Surg. 2008;26(6):579-83.

Buonocore MG. A simple method of increasing the adhesion of acrylic filling materials to enamel surfaces. J Dent Res. 1955;34(6):849-53.

Carrilho MR, Geraldeli S, Tay F, de Goes MF, Carvalho RM, Tjaderhane L, et al. In vivo preservation of the hybrid layer by chlorhexidine. J Dent Res. 2007;86(6):529-33.

Carvalho RM. Sistemas adesivos: fundamentos para aplicação clínica. Biodonto. 2004;2(1).

Ceballos L, Osorio R, Toledano M, Marshall GW. Microleakage of composite restorations after acid or Er:YAG laser cavity treatments. Dent Mater. 
2001;17(4):340-6 .

Ceballos L, Toledano M, Osorio R, Tay FR, Marshall GW. Bonding to Er-YAG-lasertreated dentin. J Dent Res. 2002;81(2):119-22.

Corona SAM, Borsatto MC, Pecora JD, Rocha R, Ramos TS, Palma-Dibb RG. Assessing microleakage of different class $\mathrm{V}$ restorations after Er:YAG laser and bur preparation. J Oral Rehabil. 2003;30(10):1008-14.

Correa-Afonso AM, Ciconne-Nogueira JC, Pecora JD, Palma-Dibb RG. In vitro assessment of laser efficiency for caries prevention in pits and fissures. Microsc Res Tech. 2012;75(2):245-52.

De Munck J, Mine A, Poitevin A, Van Ende A, Cardoso MV, Van Landuyt KL, et al. Meta-analytical review of parameters involved in dentin bonding. J Dent Res. 2012;91(4):351-7

De Munck J, Van Meerbeek B, Yudhira R, Lambrechts P, Vanherle G. Micro-tensile bond strength of two adhesives to Erbium : YAG-lased vs. bur-cut enamel and dentin. Eur J Oral Sci. 2002;110(4):322-9.

Delfino CS, Souza-Zaroni WC, Corona SAM, Palma-Dibb RG. Microtensile bond strength of composite resin to human enamel prepared using Erbium : Yttrium Aluminum Garnet laser. J Biomed Mater Res A. 2007;80(2):475-9.

Dostalova T, Jelinkova $H$, Kucerova $H$, Krejsa O, Hamal K, Kubelka J, et al. Noncontact Er:YAG laser ablation: Clinical evaluation. J Clin Laser Med Surg. 1998;16(5):273-82.

Dunn WJ, Davis JT, Bush AC. Shear bond strength and SEM evaluation of composite bonded to Er:YAG laser-prepared dentin and enamel. Dent Mater. 2005;21(7):616-24.

Eick JD, Wilko RA, Anderson CH, Sorensen SE. Scanning electron microscopy of cut tooth surfaces and identification of debris by use of the electron microprobe. J Dent Res. 1970;49(6):Suppl:1359-68.

Erickson RL. Mechanism and clinical implications of bond formation for two dentin bonding agents. Am J Dent. 1989;2 Spec No:117-23.

Esteves-Oliveira M, Carvalho WL, Eduardo CdP, Zezell DM. Influence of the Additional Er:YAG Laser Conditioning Step on the Microleakage of Class V Restorations. J Biomed Mater Res B Appl Biomater. 2008;87(2):538-43.

Ferracane JL. Resin composite-State of the art. Dent Mater. 2011;27(1):29-38.

Flury S, Koch T, Peutzfeldt A, Lussi A. Micromorphology and adhesive performance of Er:YAG laser-treated dentin of primary teeth. Lasers Med Sci. 2012;27(3):529-35.

Franke M, Taylor AW, Lago A, Fredel MC. Influence of Nd:YAG laser irradiation on 
an adhesive restorative procedure. Oper Dent. 2006;31(5):604-9.

Fusayama T, Nakamura M, Kurosaki N, Iwaku M. Non-pressure adhesion of a new adhesive restorative resin. J Dent Res. 1979;58(4):1364-70.

Goncalves SEP, De Araujo MAM, Damiao AJ. Dentin bond strength: Influence of laser irradiation, acid etching, and hypermineralization. J Clin Laser Med Surg. 1999;17(2):77-85.

Gordan VV, Vargas MA, Cobb DS, Denehy GE. Evaluation of adhesive systems using acidic primers. Am J Dent. 1997;10(5):219-23.

Gwinnett AJ, Matsui A. A study of enamel adhesives. The physical relationship between enamel and adhesive. Arch Oral Biol. 1967;12(12):1615-20.

Hebling J, Pashley DH, Tjaderhane L, Tay FR. Chlorhexidine arrests subclinical degradation of dentin hybrid layers in vivo. J Dent Res. 2005;84(8):741-6.

Hibst R, Keller U. Experimental studies of the application of the Er:YAG laser on dental hard substances: I. Measurement of the ablation rate. Lasers Surg Med. 1989;9(4):338-44.

Huang GF, Lan WH, Guo MK, Chiang CP. Synergistic effect of Nd:YAG laser combined with fluoride varnish on inhibition of caries formation in dental pits and fissures in vitro. J Formos Med Assoc. 2001;100(3):181-5.

Keller U, Hibst R, Geurtsen W, Schilke R, Heidemann D, Klaiber B, et al. Erbium:YAG laser application in caries therapy. Evaluation of patient perception and acceptance. J Dent. 1998;26(8):649-56.

Lee B-S, Lin P-Y, Chen M-H, Hsieh T-T, Lin C-P, Lai J-Y, et al. Tensile bond strength of ErCr:YSGG laser-irradiated human dentin and analysis of dentin-resin interface. Dent Mater. 2007;23(5):570-8.

Luk K, Tam L, Hubert M. Effect of light energy on peroxide tooth bleaching. J Am Dent Assoc. 2004;135(2):194-201; quiz 228-9.

Lussi A, Imwinkelried S, Pitts N, Longbottom C, Reich E. Performance and reproducibility of a laser fluorescence system for detection of occlusal caries in vitro. Caries Res. 1999;33(4):261-6.

Lussi A, Megert B, Longbottom C, Reich E, Francescut P. Clinical performance of a laser fluorescence device for detection of occlusal caries lesions. Eur J Oral Sci. $2001 ; 109(1): 14-9$.

Maiman TH. Stimulated optical radiation in ruby. Nature. 1960;187(4736):493-4.

Malta DAMP, Costa MM, Pelino JEP, de Andrade ME, Lizarelli RFZ. Bond strength of an adhesive system irradiated with Nd:YAG laser in dentin treated with Er:YAG laser. Laser Phys Lett. 2008;5(2):144-50. 
Manhaes LA, Oliveira DC, Marques MM, Matos AB. Influence of Er:YAG laser surface treatment and primer application methods on microtensile bond strength selfetching systems. Photomed Laser Surg. 2005;23(3):304-12.

Marimoto A, Cunha L, Yui K, Huhtala M, Barcellos D, Prakki A, et al. Influence of Nd:YAG Laser on the Bond Strength of Self-etching and Conventional Adhesive Systems to Dental Hard Tissues. Oper Dent. In Press 2012.

Marson FC, Sensi LG, Vieira LC, Araujo E. Clinical evaluation of in-office dental bleaching treatments with and without the use of light-activation sources. Oper Dent. 2008;33(1):15-22.

Martinez-Insua A, Dominguez LD, Rivera FG, Santana-Penin UA. Differences in bonding to acid-etched or Er:YAG-laser-treated enamel and dentin surfaces. J Prosthet Dent. 2000;84(3):280-8.

Matos AB, Oliveira DC, Kuramoto M, Jr., Eduardo CP, Matson E. Nd:YAG laser influence on sound dentin bond strength. J Clin Laser Med Surg. 1999;17(4):165-9.

Matos AB, Oliveira DC, Navarro RS, de Eduardo CP, Matson E. Nd:YAG laser influence on tensile bond strength of self-etching adhesive systems. J Clin Laser Med Surg. 2000;18(5):253-7.

Mertz-Fairhurst EJ, Curtis JW, Ergle JW, Rueggeberg FA, Adair SM. Ultraconservative and cariostatic sealed restorations: Results at year 10. J Am Dent Assoc. 1998;129(1):55-66.

Mjor IA, Dahl JE, Moorhead JE. Age of restorations at replacement in permanent teeth in general dental practice. Acta Odontol Scand. 2000;58(3):97-101.

Mondelli RF, Azevedo JF, Francisconi AC, Almeida CM, Ishikiriama SK. Comparative clinical study of the effectiveness of different dental bleaching methods - two year follow-up. J Appl Oral Sci. 2012;20(4):435-43.

Moritz A, Gutknecht N, Schoop U, Goharkhay K, Wernisch J, Sperr W. Alternatives in enamel conditioning: a comparison of conventional and innovative methods. J Clin Laser Med Surg. 1996;14(3):133-6.

Nakabayashi N, Kojima K, Masuhara E. The promotion of adhesion by the infiltration of monomers into tooth substrates. J Biomed Mater Res. 1982;16(3):265-73.

Oliveira DC, Manhaes LA, Marques MM, Matos AB. Microtensile bond strength analysis of different adhesive systems and dentin prepared with high-speed and $\mathrm{Er}$ : YAG laser: A comparative study. Photomed Laser Surg. 2005;23(2):219-24.

Pashley DH, Sano H, Ciucchi B, Yoshiyama M, Carvalho RM. Adhesion testing of dentin bonding agents: a review. Dent Mater. 1995;11(2):117-25. 57.

Pashley DH, Tay FR, Yiu C, Hashimoto M, Breschi L, Carvalho RM, et al. Collagen 
degradation by host-derived enzymes during aging. J Dent Res. 2004;83(3):216-21 .

Pashley DH, Tay FR, Breschi L, Tjaderhane L, Carvalho RM, Carrilho M, et al. State of the art etch-and-rinse adhesives. Dent Mater. 2011;27(1):1-16.

Perinka L, Sano H, Hosoda H. Dentin thickness, hardness, and Ca-concentration vs bond strength of dentin adhesives. Dent Mater. 1992;8(4):229-33.

Pinheiro ALB, Brugnera Júnior A, Zanin FAA. Aplicação do Laser na Odontologia. São Paulo: Editora Santos; 2010.

Raucci-Neto W, De Castro LM, Correa-Afonso AM, Da Silva RS, Pecora JD, PalmaDibb RG. Assessment of thermal alteration during class $V$ cavity preparation using the Er:YAG laser. Photomed Laser Surg. 2007;25(4):281-6.

Retief DH. Standardizing laboratory adhesion tests. Am J Dent. 1991;4(5):231-6.

Sano H, Shono T, Sonoda H, Takatsu T, Ciucchi B, Carvalho R, et al. Relationship between surface area for adhesion and tensile bond strength evaluation of a microtensile bond test. Dent Mater. 1994;10(4):236-40.

Scherrer SS, Cesar PF, Swain MV. Direct comparison of the bond strength results of the different test methods: a critical literature review. Dent Mater. 2010;26(2):e78-93.

Soncini JA, Maserejian NN, Trachtenberg F, Tavares M, Hayes C. The. longevity of amalgam versus compomer/composite restorations in posterior primary and permanent teeth - Findings from the new England children's amalgam trial. J Am Dent Assoc. 2007;138(6):763-72.

Spencer P, Ye Q, Park J, Topp EM, Misra A, Marangos O, et al. Adhesive/Dentin Interface: The Weak Link in the Composite Restoration. Ann Biom Eng. 2010;38(6):1989-2003.

Stern RH, Sognnaes RF. Laser beam effect on dental hard tissues. J Dent Res. 1964;43(5SP):873-\&.

Tachibana A, Marques MM, Pavan Soler JM, Matos AB. Erbium, chromium : yttrium scandium gallium garnet laser for caries removal: influence on bonding of a selfetching adhesive system. Lasers Med Sci. 2008;23(4):435-41.

Tay FR, Pashley DH, Suh BI, Carvalho RM, Itthagarun A. Single-step adhesives are permeable membranes. J Dent. 2002;30(7-8):371-82.

Tay FR, Pashley DH, Yoshiyama M. Two modes of nanoleakage expression in single-step adhesives. J Dent Res. 2002;81(7):472-6.

Tipler PA, Mosca G. Física para cientistas e engenheiros. São Paulo: Livros Técnicos e Científicos Editora Ltda; 2009.

Tjaderhane L, Nascimento FD, Breschi L, Mazzoni A, Tersariol IL, Geraldeli S, et al. 
Optimizing dentin bond durability: Control of collagen degradation by matrix metalloproteinases and cysteine cathepsins. Dent Mater. 2013;29(1):116-35.

Torres CP, Gomes-Silva JM, Borsatto MC, Barroso JM, Pecora JD, Palma-Dibb RG. Shear bond strength of self-etching and total-etch adhesive systems to Er:YAG laserirradiated primary dentin. J Dent Child (Chic). 2009;76(1):67-73.

Tyas MJ, Anusavice KJ, Frencken JE, Mount GJ. Minimal intervention dentistry - a review - FDI Commission Project 1-97. Int Dent J. 2000;50(1):1-12.

Van Meerbeek B, Peumans M, Poitevin A, Mine A, Van Ende A, Neves A, et al. Relationship between bond-strength tests and clinical outcomes. Dent Mater. 2010;26(2):e100-21

Van Meerbeek B, Yoshihara K, Yoshida Y, Mine A, De Munck J, Van Landuyt KL. State of the art of self-etch adhesives. Dent Mater. 2011;27(1):17-28.

Visuri SR, Walsh JT, Wigdor HA. Erbium laser ablation of dental hard tissue: Effect of water cooling. Lasers Surg Med. 1996;18(3):294-300.

Yaman BC, Guray BE, Dorter C, Gomec Y, Yazicioglu O, Erdilek D. Effect of the erbium:yttrium-aluminum-garnet laser or diamond bur cavity preparation on the marginal microleakage of class $\mathrm{V}$ cavities restored with different adhesives and composite systems. Lasers Med Sci. 2012;27(4):785-94.

Zach L, Cohen G. Pulp response to externally applied heat. Oral Surg Oral Med Oral Pathol. 1965;19:515-30. 
Apêndices 

APÊNDICE A - Termo de doação de dentes humanos por cirurgião-dentista

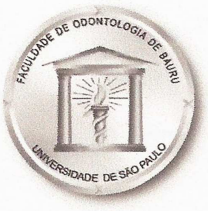

\section{Universidade de São Paulo \\ Faculdade de Odontologia de Bauru}

A1. Dr. Octávio Pinheiro Brisolla, 9-75 - Bauru-SP - CEP 17012-901 - C.P. 73

PABX (0XX14)3235-8000 - FAX (0XX14)3223-4679

TERMO DE DOAÇÃO DE DENTES HUMANOS POR CIRURGIÕES-DENTISTAS

Eu, Nawro conoty responsável pelo atendimento no setor de urgência da Faculdade de Odontologia de Bauru da Universidade de São Paulo, dôo 80 terceiros molares a fim de contribuir para a realização da pesquisa intitulada "Resistência de união à dentina e sistemas adesivos irradiados com laser de diodo: estudo in vitro.", de autoria de Rafael Massunari Maenosono, Regina Guenka Palma-Dibb e Sérgio Kiyoshi Ishikiriama. Declaro que estes dentes serão extraídos por indicação terapêutica, cujos históricos farão parte dos prontuários dos pacientes de quem se originam. Estou ciente de que - material a ser recolhido será utilizado pelos pesquisadores desta Faculdade unicamente para a realização da presente pesquisa.
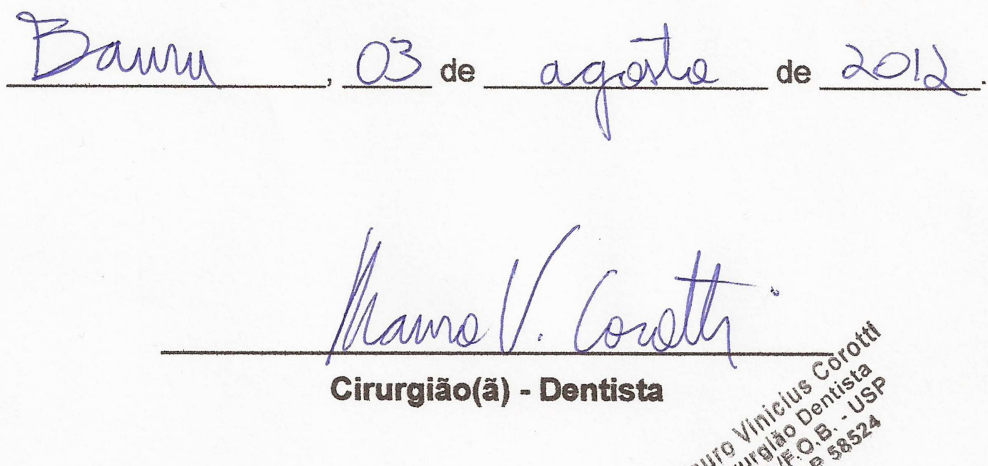
APÊNDICE B - Tabela com as médias dos valores de resistência de união obtidos para cada dente testado

\begin{tabular}{cccccccc}
\hline MP & MP-L & SB & SB-L & CSE & CSE-L & EO & EO-L \\
\hline 34,887 & 39,592 & 20,583 & 40,707 & 35,211 & 39,264 & 16,032 & 30,310 \\
33,144 & 44,212 & 38,795 & 48,271 & 43,392 & 37,645 & 15,610 & 25,062 \\
28,857 & 45,441 & 30,428 & 63,184 & 52,319 & 35,742 & 18,186 & 46,844 \\
26,526 & 41,733 & 39,006 & 40,516 & 30,417 & 28,255 & 28,881 & 24,890 \\
35,970 & 26,579 & 28,601 & 41,573 & 59,252 & 46,131 & 25,386 & 33,204 \\
35,983 & 26,898 & 43,949 & 33,375 & 59,892 & 33,427 & 20,742 & 26,708 \\
59,121 & 33,958 & 28,990 & 46,908 & 27,861 & 32,749 & 20,094 & 20,995 \\
48,291 & 27,379 & 35,189 & 43,505 & 50,699 & 30,373 & 15,635 & 30,869 \\
43,232 & 38,494 & 37,764 & 36,190 & 16,076 & 42,740 & 9,815 & 28,998 \\
54,963 & 33,957 & 31,625 & 42,660 & 61,937 & 53,200 & 26,351 & 30,841 \\
\hline
\end{tabular}


APÊNDICE C - Aplicação de ANOVA a dois critérios, seguido de Tukey para comparações individuais.

Univariate Tests of Significance for resistência (MPa)

Sigma-restricted parameterization

Effective hypothesis decomposition

\begin{tabular}{|l|r|r|r|r|c|}
\hline & \multicolumn{1}{|c|}{ SS } & \multicolumn{1}{c|}{ Degr. of } & \multicolumn{1}{c|}{ MS } & \multicolumn{1}{c|}{$\mathrm{F}$} & \multicolumn{1}{c|}{$\mathrm{p}$} \\
\hline Intercept & 101038,2 & 1 & 101038,2 & 1202,093 & 0,000000 \\
\hline material & 3181,6 & 3 & 1060,5 & 12,618 & 0,000001 \\
\hline laser & 134,4 & 1 & 134,4 & 1,599 & 0,210142 \\
\hline${\text { material}{ }^{\star} \text { laser }}^{1162,3}$ & 3 & 387,4 & 4,609 & 0,005246 \\
\hline Error & 6051,7 & 72 & 84,1 & & \\
\hline
\end{tabular}

Tukey HSD test; variable resistência (MPa)

Approximate Probabilities for Post Hoc Tests

Error: Between MS $=84,052, \mathrm{df}=72,000$

\begin{tabular}{|c|c|c|c|c|c|c|c|c|c|c|}
\hline & material & laser & $\{1\}$ & $\{2\}$ & $\{3\}$ & $\{4\}$ & $\{5\}$ & $\{6\}$ & $\{7\}$ & $\{8\}$ \\
\hline 1 & MP & $\mathrm{SL}$ & & 0,966180 & 0,742351 & 0,987369 & 0,987022 & 0,999538 & 0,000219 & 0,214867 \\
\hline 2 & MP & $\mathrm{L}$ & 0,966180 & & 0,999175 & 0,543374 & 0,540658 & 0,999561 & 0,004493 & 0,829747 \\
\hline 3 & SB & $\mathrm{SL}$ & 0,742351 & 0,999175 & & 0,217924 & 0,216184 & 0,957453 & 0,025327 & 0,986753 \\
\hline 4 & $\mathrm{SB}$ & $\mathrm{L}$ & 0,987369 & 0,543374 & 0,217924 & & 1,000000 & 0,854798 & 0,000125 & 0,025380 \\
\hline 5 & CSE & $\overline{\mathrm{SL}}$ & 0,987022 & 0,540658 & 0,216184 & 1,000000 & & 0,852937 & 0,000125 & 0,025088 \\
\hline 6 & CSE & $\mathrm{L}$ & 0,999538 & 0,999561 & 0,957453 & 0,854798 & 0,852937 & & 0,000852 & 0,508388 \\
\hline 7 & EO & $\mathrm{SL}$ & 0,000219 & 0,004493 & 0,025327 & 0,000125 & 0,000125 & 0,000852 & & 0,217611 \\
\hline 8 & EO & $\mathrm{L}$ & 0,214867 & 0,829747 & 0,986753 & 0,025380 & 0,025088 & 0,508388 & 0,217611 & \\
\hline
\end{tabular}


APÊNDICE D - Aplicação de múltiplos testes "t" para comparações individuais entre grupos CONTROLE e LASER para cada sistema adesivo.

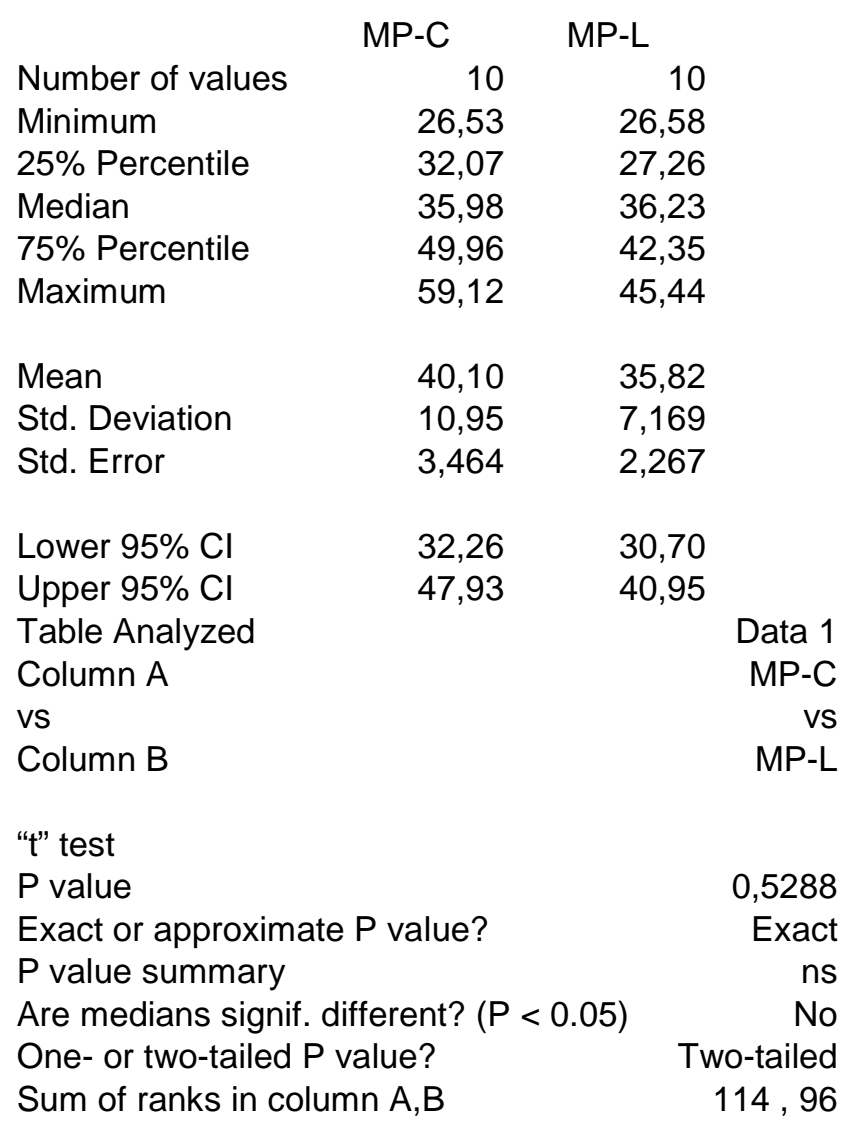




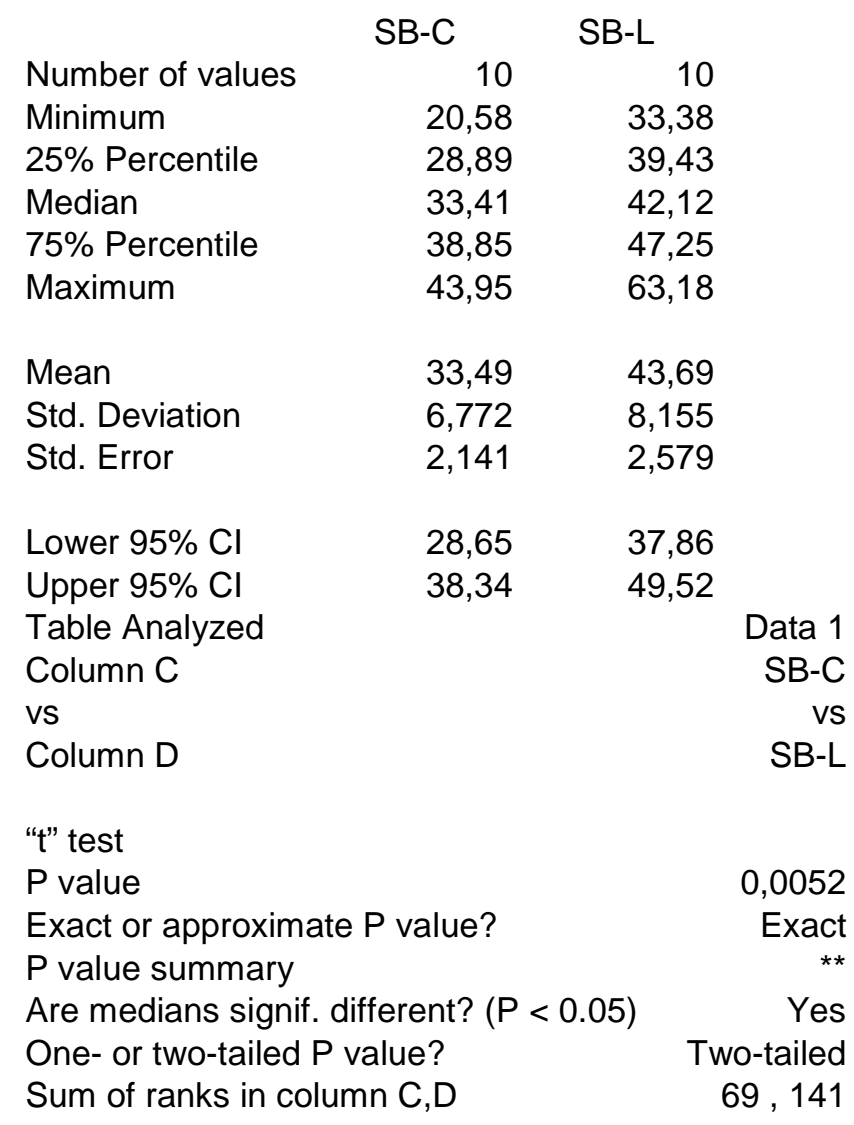


Number of values

CSE-C CSE-L

Minimum

$16,08 \quad 28,26$

25\% Percentile

Median

$29,78 \quad 32,16$

75\% Percentile

$47,05 \quad 36,69$

Maximum

$59,41 \quad 43,59$

$61,94 \quad 53,20$

Mean

$43,71 \quad 37,95$

Std. Deviation

Std. Error

15,71

7,660

$4,969 \quad 2,422$

Lower 95\% Cl

$32,46 \quad 32,47$

Upper 95\% Cl

54,95

43,43

Table Analyzed

Data 1

Column E

CSE-C

vs

Column F

CSE-L

"t' test

$P$ value

Exact or approximate $\mathrm{P}$ value?

$P$ value summary

Are medians signif. different? $(P<0.05)$

One- or two-tailed $P$ value?

Sum of ranks in column E,F

0,3930

Exact

ns

No

Two-tailed

117,93 


\begin{tabular}{|c|c|c|c|}
\hline \multirow[b]{2}{*}{ Number of values } & \multicolumn{3}{|c|}{ EO-C EO-L } \\
\hline & 10 & 10 & \\
\hline Minimum & 9,815 & 21,00 & \\
\hline $25 \%$ Percentile & 15,63 & 25,02 & \\
\hline Median & 19,14 & 29,65 & \\
\hline 75\% Percentile & 25,63 & 31,45 & \\
\hline Maximum & 28,88 & 46,84 & \\
\hline Mean & 19,67 & 29,87 & \\
\hline Std. Deviation & 5,858 & 6,983 & \\
\hline Std. Error & 1,852 & 2,208 & \\
\hline Lower 95\% Cl & 15,48 & 24,88 & \\
\hline Upper 95\% Cl & 23,86 & 34,87 & \\
\hline Table Analyzed & & & Data 1 \\
\hline Column G & & & EO-C \\
\hline vs & & & vs \\
\hline Column H & & & EO-L \\
\hline "t" test & & & \\
\hline$P$ value & & & 0,0015 \\
\hline Exact or approxim & alue? & & Exact \\
\hline$P$ value summary & & & . \\
\hline Are medians signi & ent? $(P<0.05)$ & & Yes \\
\hline One- or two-tailed & & & o-tailed \\
\hline Sum of ranks in $\mathrm{cc}$ & $\mathrm{A}, \mathrm{H}$ & & 65,145 \\
\hline
\end{tabular}



Anexos 

ANEXO A - Parecer Consubstanciado do CEP

\section{FACULDADE DE ODONTOLOGIA DE BAURU-}

\section{PROJETO DE PESQUISA}

Título: Resistência de união à dentina de sistemas adesivos irradiados com laser de diodo: estudo in vitro

Área Temática:

Área 9. A critério do CEP

Versão: 2

CAAE: $\quad 05737812.7 .0000 .5417$

Pesquisador: Rafael Massunari Maenosono

Instituição: Faculdade de Odontologia de Bauru-USP

\section{PARECER CONSUBSTANCIADO DO CEP}

$\begin{array}{lc}\text { Número do Parecer: } & 111.666 \\ \text { Data da Relatoria: } & 26 / 09 / 2012\end{array}$

Apresentação do Projeto:

Título: "Resistência de união à dentina de sistemas adesivos irradiados com LASER de diodo: estudo in vitro"

\section{Objetivo da Pesquisa:}

avaliar o efeito da irradiação do LASER de Diodo sobre diferentes sistemas adesivos, na resistência adesiva à dentina.

\section{Avaliação dos Riscos e Benefícios:}

Risco: o estudo não oferece riscos ao sujeito da pesquisa uma vez que serão utilizados os dentes já extraídos por razões terapêuticas.

Benefício:o trabalho visa a obtenção de uma adesão mais efetiva entre materiais restauradores e dente, a fim de reduzir ou evitar falhas deste material na restauração de dentes.

\section{Comentários e Considerações sobre a Pesquisa:}

Trata-se de uma investigação interessante, aliando a tecnologia do laser ao procedimento restaurador, com o intuito de otimizar a performance do material adesivo já existente no mercado, que ainda apresenta deficiências quando usado sem essa associação proposta. É um passo inicial que poderá ser seguido de outros trabalhos complementares, visando a aplicação clínica futura.

Considerações sobre os Termos de apresentação obrigatória:

Foram apresentados todos os documentos obrigatórios. Com relação à observação feita, sobre a necessidade de anexar outros termos de doação, devido à colaboração de outros profissionais doando dentes à pesquisa, eles não foram necessários. Somente o Serviço de Urgência da FOB, foi responsável pela doação, e o termo de doação deste serviço já havia sido apresentado.

\section{Recomendações:}

Todas as recomendaç̃es feitas foram acatadas:

- correção do título;

- correção da metodologia, indicando o Serviço de Urgência como o único responsável pela doação dos dentes;

- correção no cronograma com relação ao prazo para a coleta de dentes; prazo para a redação da dissertação e adequação deste cronograma nos dois documentos que apresentam o projeto de pesquisa (Plataforma Brasil e em texto);

Endereço: DOUTOR OCTAVIO PINHEIRO BRISOLLA 75 QUADRA 9

Bairro: VILA NOVA CIDADE UNIVERSITARIA CEP: $17.012-901$

UF: SP Município: BAURU

Telefone: (14)3235-8356 Fax: (14)3235-8356 E-mail: mferrari@fob.usp.br 


\section{FACULDADE DE ODONTOLOGIA DE BAURU-}

- correção da descrição dos grupos, que são 8 no total, sem subgrupos, como havia sido redigido no item Resumo do "Detalhamento do Estudo"(Plataforma Brasil);

- descrição da composição dos grupos no item "Metodologia Proposta", que só era apresentada sem detalhes, no "Resumo"

Conclusões ou Pendências e Lista de Inadequações:

Esse trabalho de pequisa apresenta uma idéia bastante interessante com possibilidade de aplicação prática em futuro próximo. Todas as falhas apontadas na descrição do projeto e na apresentação dos documentos necessários, foram devidamente corrigidas.

Situação do Parecer:

Aprovado

Necessita Apreciação da CONEP:

Não

Considerações Finais a critério do CEP:

O CEP acata o parecer do relator.

Esse projeto foi considerado APROVADO. O CEP-FOB/USP exige a apresentação de relatórios anuais (parciais e finais), conforme o cronograma apresentado. Qualquer alteração na metodologia e/ou título e a inclusão ou exclusão de autores deverá ser prontamente comunicada. Lembramos que na apresentação do relatório final, deverão ser incluídos todos os TCLEs e/ou termos de doação de dentes devidamente assinados e rubricados.

BAURU, 01 de Outubro de 2012

Assinado por:

Maria Teresa Atta

(Coordenador)

Endereço: DOUTOR OCTAVIO PINHEIRO BRISOLLA 75 QUADRA 9

Bairro: VILA NOVA CIDADE UNIVERSITARIA CEP: $17.012-901$

UF: SP Município: BAURU

E-mail: mferrari@fob.usp.br 